\title{
Physical Properties and Internal Structure of the Central Region of the Moon
}

\author{
O. L. Kuskov ${ }^{a, *}$, E. V. Kronrod ${ }^{a, * *}$, K. Matsumoto ${ }^{b, c, * * *}$, and V. A. Kronrod ${ }^{a, * * * *}$ \\ ${ }^{a}$ Vernadsky Institute of Geochemistry and Analytical Chemistry, Russian Academy of Sciences, Moscow, 119991 Russia \\ ${ }^{b}$ RISE Project, National Astronomical Observatory of Japan, 2-12, Hoshigaoka, Mizusawa, Oshu, Iwate 023-0861, Japan \\ ${ }^{c}$ Graduate University for Advanced Studies, SOKENDAI, Shonan Village, Hayama, Kanagawa 240-0193, Japan \\ *e-mail: ol_kuskov@mail.ru \\ **e-mail:e.kronrod@gmail.com \\ ***e-mail: koji.matsumoto@nao.ac.jp \\ ****e-mail:va kronrod@mail.ru
}

Received April 30, 2021; revised June 4, 2021; accepted June 10, 2021

\begin{abstract}
One of the pivoting problems of the geochemistry and geophysics of the Moon is the structure of its central region, i.e., its core and adjacent transition layer located at the boundary between the solid mantle and liquid or partially molten core. The chemical composition of the mantle and the internal structure of the central region of the Moon were simulated based on the joint inversion of seismic, selenophysical, and geochemical parameters that are not directly interrelated. The solution of the inverse problem is based on the Bayesian approach and the use of the Markov chain Monte Carlo algorithm in combination with the method of Gibbs free energy minimization. The results show that the radius of the Moon's central region is about $500-550 \mathrm{~km}$. The thickness of the transition layer and the radii of the outer and inner cores relatively weakly depend on the composition models of the bulk silicate Moon with different contents of refractory oxides. The silicate portion of the Moon is enriched in FeO (12-13 wt \%, FeO 1.5 × BSE) and depleted in $\mathrm{MgO}(\mathrm{Mg} \#$ 79-81) relative to the bulk composition of the silicate Earth (BSE), which is in conflict with the possibility of the formation of the Moon from the Earth's primitive mantle and does not find an adequate explanation in the current canonical and non-canonical models of the origin of the $\mathrm{Moon}_{\text {. }} \mathrm{SiO}_{2}$ concentrations in all zones of the lunar mantle vary insignificantly and amount to $52-53 \mathrm{wt} \%$, and the predominant mineral of the upper mantle is low-Ca orthopyroxene but not olivine. With respect to $\mathrm{Al}_{2} \mathrm{O}_{3}$, the lunar mantle is stratified, with a $\mathrm{Al}_{2} \mathrm{O}_{3}$ content higher in the lower mantle than in all overlying shells. The partially molten transition layer surrounding the core is about $200-250 \mathrm{~km}$ thick. The radii of the solid inner core are within $50-250 \mathrm{~km}$, and the most probable radii of the liquid outer core are $\sim 300-350 \mathrm{~km}$. The physical characteristics of the lunar core are compared with experimental measurements of the density and speed of sound of liquid $\mathrm{Fe}(\mathrm{Ni})-\mathrm{S}-\mathrm{C}-\mathrm{Si}$ alloys. If the seismic model of the liquid outer core with $V_{P}=4100 \pm 200 \mathrm{~m} / \mathrm{s}$ (Weber et al., 2011) is reasonably reliable, then this uncertainty range is in the best agreement with the $V_{P}$ values of $3900-4100 \mathrm{~m} / \mathrm{s}$ of liquid $\mathrm{Fe}(\mathrm{Ni})-\mathrm{S}$ alloys, with sulfur content up to $\sim 10 \mathrm{wt} \%$ and a density of $6200-7000 \mathrm{~kg} / \mathrm{m}^{3}$, as well as with the inverted values of density and velocity of the outer core. The $V_{P}$ values of liquid $\mathrm{Fe}-\mathrm{Ni}-\mathrm{C}$ and $\mathrm{Fe}-\mathrm{N}-\mathrm{Si}$ alloys at $5 \mathrm{GPa}$ exceed seismic estimates of the speed of sound of the outer lunar core, which indicates that carbon and silicon can hardly be dominant light elements of the lunar core. The inner $\mathrm{Fe}(\mathrm{Ni})$ core (possibly with an insignificant content of light elements: sulfur and carbon) is presumably solid and has a density of $7500-7700 \mathrm{~kg} / \mathrm{m}^{3}$. The difference in density between the inner and outer cores $\Delta \rho \sim 500-1000 \mathrm{~kg} / \mathrm{m}^{3}$ can be explained by the difference in their composition.
\end{abstract}

Keywords: Moon, speed of sound, density, $\mathrm{Fe}-\mathrm{Ni}-\mathrm{S}-\mathrm{C}-\mathrm{Si}$ liquids, transition layer, mantle, core DOI: $10.1134 /$ S0016702921110069

\section{INTRODUCTION}

One of the key problems of planetology and geochemistry is the origin and composition of the Moon. Understanding of these issues is important not only per se but also in the context of the still poorly understood origin of the Earth-Moon system (Urey, 1951; Levin and Maeva, 1975; Ruskol, 1997; Galimov, 1995;
Discussion Meeting Issue, 2014; Canup, 2014; Nielsen et al., 2021). The Moon is the only cosmic body of the Solar System (other than the Earth) whose rock samples have been studied and on which seismic data have been acquired. The chemical composition, interpretations of the inner structure, and physical state of the Moon strongly depended on models assumed for the origin of this body, its thermal regime, and its large- 
scale chemical and magmatic differentiation. Studies of the Moon were launched five decades ago, in the 20th century, with the application of space missions, such as Luna, Apollo, Clementine, and Lunar Prospector, and were continued in the 21st century by the probes LRO (Lunar Reconnaissance Orbiter), GRAIL (Gravity Recovery and Interior Laboratory), Kaguya/SELENE, Chang' E, and Chandrayaan, which made it possible to carry out topographic, mineralogical, and gravitational mapping of the Moon's surface and to understand some structural features of the interiors of the Moon. Data thus acquired led to conclusions that were of paramount importance for lunar geology, geochemistry, and geophysics (Wieczorek et al., 2006; Lognonné, 2005; Khan et al., 2014; Williams et al., 2014; Xiao and Head, 2020) but nevertheless failed to provide reliable arguments for interpreting the origin of the Moon, its chemical composition, inner structure, the physical state of its central region, and the size of its core. Many issues concerning the origin of the Moon and its thermochemical evolution remain disputable until nowadays.

Dynamic models of the development of the Moon are contradictory. Each of them (separation from the Earth, origin of the Moon from a swarm of bodies revolving around the Earth, megaimpact, microimpacts, the model of synestia, and the model of the origin of the Moon by means of fragmentation of the lowdensity protoplanetary accumulation) provide some arguments to solve this problem, but none of these models is able to reasonably well explain some features of lunar geochemistry because of the absence of an adequate solution for combining the isotope identity of some elements (oxygen, silicon, titanium, and tungsten), depletion of volatile and siderophile elements, reasonably convincing estimation of the impactor composition and impact parameters, the mass ratio of the impactor and target or the mass fraction captured by the swarm when the two bodies collided, the significant differences in the abundances of $\mathrm{FeO}$ and refractory elements compared to those in the bulk silicate Earth (Levin and Maeva, 1975; Ruskol, 1997; Galimov, 2011, 2019; Hartmann, 2014; Discussion Meeting Issue, 2014; Afanas'ev and Pechernikova, 2019; Canup, 2014; Hosono et al., 2019; Lock et al., 2019; Nielsen et al., 2021). E.M. Galimov (Galimov, 1995; Galimov and Krivtsov, 2012) was one of the first to start the development of a geochemical model and conducting numerical simulations of the evolution of the Earth-Moon system. The model was based on the assumption that the Earth-Moon system was produced not by a megaimpact but by means of fragmentation of a massive gas-dust accumulation, with this process resulting in relative depletion of the Moon in Fe during final accretion, the loss of volatiles, and elevated concentrations of refractory elements compared to the Earth.

Petrological-geochemical and isotope data on lunar rock samples delivered by space missions can place merely weak constraints on the physical properties of the lunar mantle, and measurements of the heat flows, selenophysical, electromagnetic, and seismic studies provide only indirect information on the composition and temperature of the lunar interiors. The problem is further complicated by the fact that the number of known parameters is smaller than the number of the unknowns, and it is hard to distinguish between the composition and temperature effects on the physical properties. Determining constraints for the composition, thermal regime, and inner structure of the Moon is still a key problem of lunar geochemistry and geophysics.

One of the criterions of the plausibility of the current hypotheses may be the composition of the bulk silicate Moon (BSM), which is a fundamental geochemical parameter in testing any cosmogonic model for the origin of the Moon. However, available Moon's soil samples fail to provide information on the composition of the Moon as a whole. The composition of deep rocks brought to the surface in the form of xenoliths could have been used (of course, with a certain proviso) to gain an insight into the composition of the Moon's primitive mantle, but regretfully, no such data are so far available for this Earth's satellite. At the same time, the Moon is the only cosmic body (along with the Earth) for which the velocities of seismic waves are known to a depth of approximately $1200 \mathrm{~km}$ (these data were acquired under the Apollo program). Seismic data are, in a sense, the "Rosetta stone" as offering important information on the Moon's inner structure (Lognonné et al., 2003; Garcia et al., 2019), but these data do not reflect its chemical composition and thus call for interpreting in terms of chemical and mineralogical composition.

It is hypothesized that the Moon is depleted in volatile (K, Rb, Cs, $\mathrm{Tl}, \mathrm{Cd}, \mathrm{Zn}$, etc.) and siderophile (Pt, Re, Ir, Os, Ni, Co, etc.) elements (Taylor et al., 2006; Galimov, 2011), whereas the concentrations of major components are still uncertain. The chemical composition of the Moon is evaluated using diverse approaches and methods: condensation and geochemical models (Morgan et al., 1978; Dauphas et al., 2014), petrological experiments (Ringwood, 1977; Snyder et al., 1992; Longhi, 2006; Sakai et al., 2014), and geophysical inversions (Kronrod and Kuskov, 2011; Khan et al., 2007; Lognonné et al., 2003). The major contradictions concern estimates of the concentrations of refractory oxides $\left(\mathrm{CaO}\right.$ and $\left.\mathrm{Al}_{2} \mathrm{O}_{3}\right)$ and $\mathrm{FeO}$ (Fig. 1), which played a decisive role in the evolution of the Moon and affected the contents and stability of the dominant mineral phases (plagioclase, olivine, pyroxenes, and garnet), physical properties, and the moment of inertia.

The geophysical models were derived with the application of a diversity of processing techniques of data provided by seismic, gravity, and electromagnetic sounding in combination with numerical simulations 


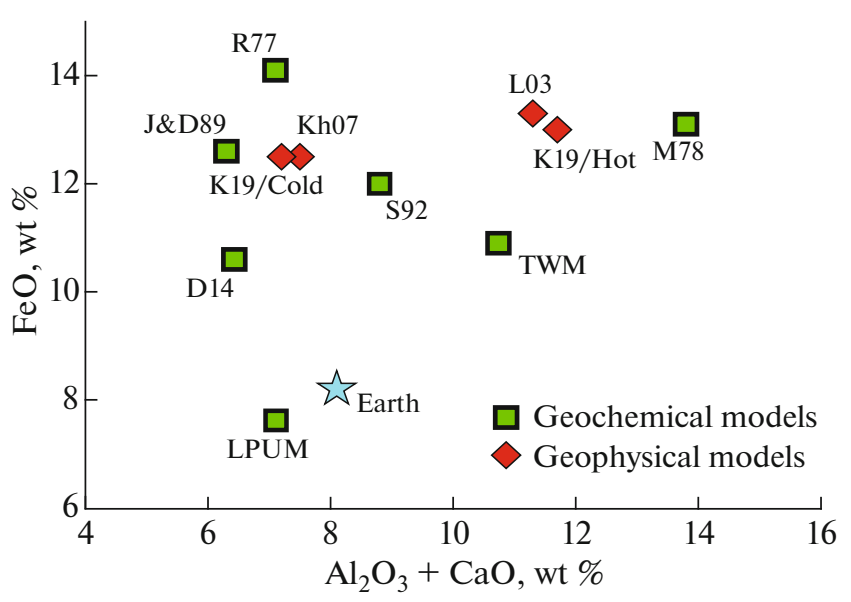

Fig. 1. Geochemical and geophysical models of the Moon's composition (crust + mantle) according to literature data in comparison with the bulk silicate Earth (marked with star in the diagram). References: M78 = Morgan et al., 1978; R77 = Ringwood, 1977; TWM = Taylor, 1982; J\&D89 = Jones and Delano, 1989; S92 = Snyder, 1992; L03 = Lognonné et al., 2003; LPUM = Longhi, 2006; Kh07 = Khan et al., 2007; D14 = Dauphas et al., 2014; K19/Cold, K19/Hot (cold and hot temperature profiles of the Moon's mantle) = Kuskov et al., 2019a, 2019b.

of phase equilibria (Khan et al., 2007, 2014; Lognonné et al., 2003; Gagnepain-Beyneix et al., 2006; Kuskov et al., 2019a, 2019b; Kronrod et al., 2018, 2019, 2020; Garcia et al., 2019).

The geochemical models are underlain by material-balance relations, analysis of the green glasses, lunar meteorites, the $\mathrm{Mg} / \mathrm{Si}, \mathrm{Al} / \mathrm{Si}, \mathrm{Mg} / \mathrm{Al}$ ratios, and correlations between the concentrations of Th, $\mathrm{U}$, and refractory oxides (Ringwood, 1977; Snyder et al., 1992; Taylor et al., 2006; Jones and Delano, 1989; Longhi, 2006; Dauphas et al., 2014). The two "polar" models for the composition of the Moon most commonly discussed in geochemical literature are (i) the TWM (Taylor Whole Moon) model, in which the Moon is approximately 50\% enriched relative to the Earth in refractory oxides (Taylor, 1982), and (ii) the LPUM (Lunar Primitive Upper Mantle) model, in which the concentrations of refractory oxides are close to those in the Earth, at $\sim 4 \% \mathrm{Al}_{2} \mathrm{O}_{3}$ (Longhi, 2006). The models offer as much as almost twice different $\mathrm{FeO}$ concentrations (Fig. 1), i.e., no consensus has been reached so far about the $\mathrm{FeO}$ concentration (Kuskov and Kronrod, 2000; Sossi and Moynier, 2017). Uncertainties in the estimates of the concentrations of major components make it possible to tailor models for the Moon both as those close to the bulk silicate Earth composition and as enriched in $\mathrm{Al}_{2} \mathrm{O}_{3}$ and $\mathrm{CaO}$. Because the seismic wave velocities and density depend on the chemical and mineralogical composition, it is reasonable to anticipate than models of the Moon with different concentrations of $\mathrm{FeO}$ and refractory oxides shall differ from one another in the distributions of density and seismic wave velocities.
Uncertainties also remain in what concerns the inner structure and physical state of the Moon's central region with parameters $T \sim 1700-2000 \mathrm{~K}$ and $P \sim$ 4.5-5 GPa. One of the key problems of the Moon's geophysics is studying its core and adjacent transition layer, which is a zone of low velocity /viscosity (LVZ, standing for the low-velocity/low-viscosity zone) and the boundary between the solid mantle and liquid or partially molten core, which can be provisionally referred to as layer $L^{\prime \prime}$, by analogy with layer D" between the Earth's core and mantle. Determining the sizes, composition, and physical properties of the Moon's central region is necessary for understanding the thermal regime, the history of the lunar dynamo, and the origin and evolution of the Moon.

Impressive progress in studying the central region of the Moon was achieved by analyzing data acquired by electromagnetic and selenophysical studies carried out by the Lunar Prospector, GRAIL, LLR, and Kaguya missions (Hood et al., 1999; Williams et al., 2001, 2014; Khan et al., 2014; Shimizu et al., 2013; Raevskiy et al., 2015). The possible occurrence of a partial melting zone in the bottom part of the Moon's mantle may follow from the absence of deep-focus moonquakes (Nakamura, 2005), from analysis of seismic data (Weber et al., 2011), and data on the Moon's laser location (Williams et al., 2001) and its gravity field (Williams et al., 2014). A seismic model of the Moon's central region without partly molted layer was proposed in (Garcia et al., 2011).

The evidence provided by petrological-geochemical analysis is more circumstantial and is partly related to the idea of lunar magma ocean (LMO). It is estimated to be constrained within the depth range from $500 \mathrm{~km}$ to the region of partial or complete melting of the whole Moon (Shearer et al., 2006). This is one of the principal still-unresolved issues of the Moon's magmatic evolution. Solutions of this problem largely depend on the composition of the mantle, seismic boundaries, and the model for Moon origin, which involve many uncertain parameters. LMO crystallization resulted in a sequence of cumulus layers consisting of various mineral assemblages, and this process was associated with the development of a light anorthosite crust underlain by a thin layer of cumulates with high $\mathrm{TiO}_{2}$ and $\mathrm{FeO}$ concentrations and, at greater depths, by a thick layer of pyroxene-olivine cumulates (Shearer et al., 2006; Xiao and Head, 2020). It is hypothesized that a density inversion can occur in these layers under certain conditions (Wieczorek et al., 2006; Yu et al., 2019; Khan et al., 2014). The gravitational instability leads to whole-mantle overturn because of the crystallization of denser ilmenite-bearing cumulates that contain radioactive elements ( $\mathrm{U}, \mathrm{Th}$, and $\mathrm{K}$ ) and generate heat. This process is favorable for the generation of deep partly molten material enriched in $\mathrm{FeO}$ and $\mathrm{TiO}_{2}$ (van Kan Parker et al., 2012; Khan et al., 2014). 
The average density of the Moon suggests that it possesses a relatively small metal core, but the composition of the latter and its physical properties and sizes are disputable. Iron deficit in the Moon is a pivoting issue in discussions of its origin (Galimov, 1995, 2019). Although seismic data are still insufficient for unambiguous identification of the inner structure of the core, the first ever constraints on the Moon's core radius were reported in (Garcia et al., 2011; Weber et al., 2011). These estimates were derived from data of the Apollo experiments, using techniques for processing seismic arrays based on the analysis of lunar seismograms with regard to waves reflected from the core.

Assuming adiabatic compression of homogeneous material, the radius of the Moon's liquid core was estimated in (Garcia et al., 2011) at $380 \pm 40 \mathrm{~km}$, and the average density was evaluated at $\rho=5.2 \pm$ $1 \mathrm{~g} / \mathrm{cm}^{3}$. The velocities of seismic waves in the liquid core have not been evaluated, and no solid inner core has been indentified, although its presence is not ruled out. A more detailed model for the central region presented in (Weber et al., 2011) includes a central region consisting of a molten layer about $150 \mathrm{~km}$ thick, with a viscosity of $2 \times 10^{16} \mathrm{~Pa}$ s (Harada et al., 2014), an outer liquid $\mathrm{Fe}-\mathrm{S}$ core, which is thought to contain $\leq 6 \mathrm{wt} \%$ sulfur and have a radius $R=330 \pm 20 \mathrm{~km}$ and $\rho=5.1 \mathrm{~g} / \mathrm{cm}^{3}$, and a solid inner core (containing an uncertain sulfur concentration) with $R=240 \pm 10 \mathrm{~km}$ and $\rho=8 \mathrm{~g} / \mathrm{cm}^{3}$. The significant differences between the models highlight the uncertainties in the interpretations of the inner structure of the central region.

The Earth's core may contain relatively much (up to $\sim 10 \mathrm{wt} \%$ ) of one or more light elements, such as $\mathrm{S}$, O, S, C, and H (Kuskov, 1981; Litasov and Shatsky, 2016). The composition of some of the terrestrial planets and large satellites (Moon, Io, Europa, and Ganymede) is often interpreted as model $\mathrm{Fe}-\mathrm{S}$ alloy (Kuskov and Kronrod, 2000; Khan et al., 2007; Weber et al., 2011; Jing et al., 2014; Lebedev et al., 2016; Morard et al., 2018; Pommier, 2018). Sulfur concentrations vary from $\sim 2 \mathrm{wt} \%$ in carbonaceous and ordinary $C O$ and $C V$ chondrites to $6 \mathrm{wt} \%$ in enstatite and carbonaceous $C I$ chondrites (Jarosewich, 1990). All light elements more or less decrease the density of solid iron alloys, whose liquidus temperatures are lower than $1800 \mathrm{~K}$ under Moon's core pressure (and depending on the $\mathrm{Si}, \mathrm{S}$, and $\mathrm{C}$ concentrations).

Experimental information on physicochemical properties of $\mathrm{Fe}$ alloys under the $P-T$ parameters of large satellites $(\sim 5-10 \mathrm{GPa}, \sim 1500-2000 \mathrm{~K})$ became available relatively recently and is still very scarce. The density of $\mathrm{Fe}-\mathrm{S}-\mathrm{C}-\mathrm{Si}$ alloys was measured by static techniques (Balog et al., 2003; Morard et al., 2018), the speed of sound was measured by ultrasonic methods (Nishida et al., 2020; Terasaki et al., 2019), and their $\mathrm{Fe}-\mathrm{S}$ solutions were simulated by methods of molecular dynamics (Belashchenko, 2014; Kuskov and Belashchenko, 2016), using the potential of the embedded atom model. A combination of methods of inelastic scattering of X-rays and X-ray diffraction was applied to estimate the densities and speed of sound of bcc-Fe and fcc-Fe (Antonangeli et al., 2015). Available theoretical and experimental data on the physical properties indicate than the Moon's core is dominated by $\mathrm{Fe}(\mathrm{Ni})$ alloy containing admixtures of $\mathrm{S}, \mathrm{C}$, and $\mathrm{Si}$ (Kuwabara et al., 2016; Terasaki et al., 2019). Current understanding of this problem is insufficient for giving preference to any of these elements.

Data on the composition and inner structure of the Moon's multilayer mantle based on the joint inversion of the integral set of gravitational, seismic, and petrological-geochemical data that are not interrelated directly with one another (Kronrod et al., 2018, 2019; Kuskov et al., 2019a, 2019b) were used in this study to analyze structural features of the deepest interiors of the satellite, namely, its central region. Analysis of the problem is based on the Bayesian approach, with the application of Markov chain Monte Carlo algorithm in combination with the method of Gibbs free energy minimization for calculating the equilibrium composition of the mineral assemblage and physical properties of the mantle as approximated by the $\mathrm{Na}_{2} \mathrm{O}-$ $\mathrm{TiO}_{2}-\mathrm{CaO}-\mathrm{FeO}-\mathrm{MgO}-\mathrm{Al}_{2} \mathrm{O}_{3}-\mathrm{SiO}_{2}$ (NaTiCFMAS) system. The principal geophysical boundary conditions were placed based on data of experiments under the Apollo program and data of the GRAIL mission aimed at studying the Moon's gravity field (seismic wave traveling time, radius, mass, moment of inertia, second-degree Love number, and monthly and annual Q-factors). This formulation is unusual in that geochemical parameters of the bulk silicate Moon are utilized as observed values to calculate the likelihood function (Khan et al., 2007; Matsumoto et al., 2015; Kronrod et al., 2018). This was done with applying constraints upon the bulk Moon composition with terrestrial $\mathrm{CaO}$ and $\mathrm{Al}_{2} \mathrm{O}_{3}$ concentrations (model $\mathrm{E}$ ) and a model with high concentrations of refractory oxides (model M). The Moon's core is modeled by the Fe-S two-component system. The geophysical models of the core are compared with experimental data on the compressibility of liquid iron alloys and speed of sound in them. The solution of the inverse problem was anticipated to yield models for the inner structure of the Moon and are best (in certain aspects) consistent with the seismic, selenophysical, and geochemical constraints.

\section{MODEL FOR THE MOON'S CHEMICAL COMPOSITION AND INNER STRUCTURE}

Herein we analyze a Maxwellian viscoelastic model of the Moon that is differentiated into shells as a result of the partial melting of an initially homogeneous body. The model of the Moon consists of nine layers (Kronrod et al., 2018): megaregolith, crust, four-layer mantle, transition layer of low velocity/viscosity (LVZ), outer 
liquid core, and inner solid core. The input parameters were data of the Apollo and GRAIL experiments and geochemical constraints placed onto the bulk Moon composition as observed data when the likelihood function was calculated (Kronrod et al., 2019).

Boundary conditions. The main boundary conditions for the inversion procedure were the following selenophysical and seismic parameters: the mass $\left(7.3463 \times 10^{22} \mathrm{~kg}\right)$, average radius $(1737.151 \mathrm{~km})$, dimensionless moment of inertia (MOI $=I_{S}=$ $\left.\left(I / M R^{2}\right)=0.393112 \pm 0.000012\right)$, second-order Love number $k_{2}=0.02422 \pm 0.00022$ (Williams et al., 2014), monthly $\left(Q_{m}=38 \pm 4\right)$ and annual $\left(Q_{a}=41 \pm 9\right)$ quality factors (Williams and Boggs, 2015), and the travel times of seismic waves (Lognonné et al., 2003), including $177 P$-waves and $125 S$-waves from 59 sources (24 deep moonquakes, 8 shallow moonquakes, 19 meteoroid impacts, and 8 artificial impacts). Inasmuch as the greatest uncertainty is involved in the seismic observations, it is assumed that an increase in the dispersion $\sigma_{\tau \mathrm{n}}$ of the travel time shall lead to a solution that is consistent with all the observed geochemical and geophysical parameters. The numerical experiments with a threefold error $\sigma_{\tau n}=3 \sigma_{\tau \mathrm{nL}}$ (relative to data in Lognonné et al., 2003) have shown a good compatibility with the geochemical and seismic constraints (Kronrod et al., 2020). All of the parameters show a normal, or almost normal, distribution. All calculation results are reported with errors $\sigma_{\tau \mathrm{n}}=3 \sigma_{\tau \mathrm{nL}}$. The Love number was calculated using the program code (Kamata et al., 2015).

Crust. In earlier publication, the crustal thickness at the Apollo 12, 14, and 16 landing sites was estimated at approximately $80 \mathrm{~km}$ (Wieczorek et al., 2006). Progress in techniques applied in analysis of Apollo seismic information and the availability of recently acquired GRAIL data on the Moon's gravity field and topography enabled acquiring more reliable estimates of the density and thickness of the crust (Lognonné et al., 2003; Wieczorek et al., 2013): the average crustal thickness varies within the range of $34-43 \mathrm{~km}$. A decrease in the crust thickness by factors of 1.5 to 2 implies the simultaneous decrease in the bulk Al oxide concentration in the Moon, which provides additional arguments in support of the theory of equal abundances of refractory elements in the Earth and Moon (Longhi, 2006; Dauphas et al., 2014). We assumed that the crust is made up of a megaregolith layer $1 \mathrm{~km}$ thick and crust itself, $34 \mathrm{~km}$ thick, whose average density is $\rho_{\text {crust }}=2590 \mathrm{~kg} / \mathrm{m}^{3}$ (Wieczorek et al., 2013). The average velocities of seismic waves in the megaregolith and crust were assumed according to the model (Weber et al., 2011), and the composition of the crust was assumed according to (Demidova et al., 2007; Taylor, 1982).

Mantle. In the absence of samples of the Moon's deep material, information on its mantle structure and composition can be derived solely from indirect sources, such as analysis of basalts and volcanic glasses, as well as sets of geophysical data. Current geochemical and geophysical models of the mantle are not always equally detailed and are fairly often mutually inconsistent, because they have been developed based on the axiomatics of different methodologies and different information data system.

All published as of yet velocity sections through the mantle that are based on data sets of the traveling times of $P$ - and $S$-waves notably differ from one another. This is explained by that inverse problems, even with a priori constraints, do not have unique solutions. Processing of data on the Apollo seismic experiments allows for a zoned inner structure of the mantle and the occurrence of a number of seismic boundaries within the Moon's interiors. Analysis of the early differentiation of the Moon and the segregation of the continental anorthosite crust, considered together with the age of lunar rocks, resulted in the LMO hypothesis, which is usually understood as the outer Moon's layer that has underwent partial melting (Shearer et al., 2006; Xiao and Head, 2020). The LMO hypothesis was utilized as an additional petrological constraint placed upon the composition of the mantle in the form of balance proportions of concentrations of major oxides (Kuskov et al., 2019a, 2019b).

The LMO hypothesis assumes that the composition of the primary lunar mantle not affected by magmatic differentiation shall be identical to the modern composition of the homogeneously mixed overlying layers (the crust and the upper and middle mantle), which were produced by LMO differentiation up to a depth of $750 \mathrm{~km}$. This depth corresponds to a sharp seismic boundary (Lognonné, 2005; GagnepainBeyneix et al., 2006). This boundary is thought to be a chemical discontinuity that marks the LMO bottom and reflects the transition from cumulates to the undifferentiated primitive mantle that has never been affected by partial melting. This assumption implies that the composition of the primary lower mantle, which is identical to the composition of the magma ocean, shall reflect the composition of the bulk silicate Moon. Differentiation to a depth of $750 \mathrm{~km}$ implies that aluminum contained in the crust has been extracted from the homogeneously mixed upper layers. According to the model (Gagnepain-Beyneix et al., 2006), the mantle is subdivided into the following four layers: $(i=1-4)$, whose boundaries occur at constant depths of 34, 250, 500, and $750 \mathrm{~km}$ : upper mantle (Mantle 1, 34-250 km), middle mantle (Mantle 2, 250-500 km + Mantle 3, 500-750 km), and lower mantle (Mantle 4, $750 \mathrm{~km}$ to the LVZ top), whose thicknesses are determined by solving the inverse problem. The viscosity of these mantle layers is assumed to be $10^{21} \mathrm{~Pa}$ s. If LMO evolved at convective stirring, then this had to led to mixing of the composition of the upper and middle mantle, whereas the primitive lower mantle did not differentiate. According to this assumption, we a priori assume that the 
chemical composition of the upper mantle layers, being equal $C($ Mantle 1$)=C($ Mantle 2$)=C($ Mantle 3$)$, is a parameter, i.e., varies at each calculation iteration (each step in the chain). At specified boundary conditions, the composition of the undifferentiated lower mantle $C$ (Mantle 4), which reflects the composition of the bulk silicate Moon (BSM), is not a parameter, depends on the concentrations of oxides in the overlying shells (crust and upper three mantle layers), and can be calculated from material-balance relations (Kronrod and Kuskov, 2011). Because the boundaries occur within the mantle at unvariable depths (250, 500 , and $750 \mathrm{~km}$ ), the mantle thickness is determined in the course of calculations, i.e., the depth of the LVZ bottom is a parameter.

Mantle temperature. Although the thermal history of the mantle is discussed in the fairly extensive literature, the temperature remains one of the most disputable and uncertain parameters of lunar interiors. Temperatures derived from thermal models are $T_{40} \sim$ $400^{\circ} \mathrm{C}$ at the crust-mantle boundary, $T_{150} \sim 500-$ $700^{\circ} \mathrm{C}, T_{500} \sim 800-1000^{\circ} \mathrm{C}$ in the upper mantle (Kuskov et al., 2014), and $T \sim 1300-1500^{\circ} \mathrm{C}$ at the core-mantle boundary (Weber et al., 2011; Khan et al., 2007). The temperature range according to literature data satisfies the constraints (Karato, 2013; Khan et al., 2014; Kronrod et al., 2019; Kuskov et al., 2019a, 219b)

$$
\begin{gathered}
450<T_{150 \mathrm{~km}}<750^{\circ} \mathrm{C}, 750<T_{500 \mathrm{~km}}<1200^{\circ} \mathrm{C}, \\
950<T_{1000 \mathrm{~km}}<1400^{\circ} \mathrm{C},
\end{gathered}
$$

(Fig. 2), and the temperature increases toward the core boundary.

The two scenarios of the thermal state of the mantle discussed in (Kuskov et al., 2019a, 2019b) correspond to cold and hot selenotherms, with $T<1400^{\circ} \mathrm{C}$ at a depth of $1400 \mathrm{~km}$, which is a temperature value lower than the solidus temperature of the pyroxenite or peridotite mantle (Ringwood and Essene, 1970). Processed GRAIL gravity data imply that temperature at the mantle-core boundary may reach (or even exceed) the solidus temperature (Khan et al., 2014; Williams et al., 2014). Calculations of the chemical composition and physical properties of the mantle within the temperature range shown in Fig. 2 are presented in (Kronrod et al., 2019). To reduce the numbers of the unknowns, the temperatures at the average depths of the upper, middle, and lower mantle are taken here up to be equal

$$
\begin{gathered}
T_{150 \mathrm{~km}}=595-605^{\circ} \mathrm{C}, T_{375 \mathrm{~km}}=755-765^{\circ} \mathrm{C}, \\
T_{625 \mathrm{~km}}=930-940^{\circ} \mathrm{C}, T_{1000 \mathrm{~km}}=1195-1205^{\circ} \mathrm{C} .
\end{gathered}
$$

Geochemical models of the composition of the Moon. The chemical composition and physical properties of each mantle zone were modeled within the framework of the $\mathrm{Na}_{2} \mathrm{O}-\mathrm{TiO}_{2}-\mathrm{CaO}-\mathrm{FeO}-\mathrm{MgO}-$

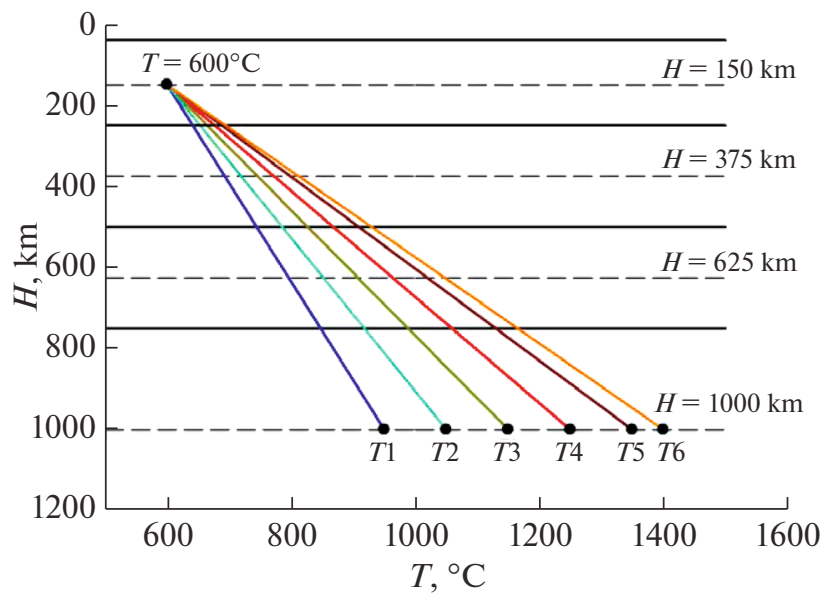

Fig. 2. Potential temperature range in the Moon's mantle.

$\mathrm{Al}_{2} \mathrm{O}_{3}-\mathrm{SiO}_{2}$ (NaTiCFMAS) system; all other details are described in (Kuskov et al.,1989; Kuskov and Kronrod, 2009; Kuskov et al., 2014). Drastic changes in composition and physical properties are allowed to occur only at zone boundaries. Within each zone, the composition, physical properties, and temperature are assumed to be constant and equal to the values at certain middle points in the vertical sections of the mantle, in combination with the natural condition that no density inversion occurs (Kronrod and Kuskov, 2011).

Based on the current understanding of the problem (Fig. 1) and with regard to geochemical contradictions between the TWM (Taylor, 1982; Taylor et al., 2006) and LPUM (Longhi, 2006) models, models for the bulk $\mathrm{Al}_{2} \mathrm{O}_{3}$ concentration $\mathrm{C}\left(\mathrm{Al}_{2} \mathrm{O}_{3}\right)$ can be classified into two types (Kronrod et al., 2018, 2019; Kuskov et al., 2019a, 2019b): models of the terrestrial type, with $3.5 \leq C_{\mathrm{E}}\left(\mathrm{Al}_{2} \mathrm{O}_{3}\right) \leq 4.5$ wt $\%$ (models $\mathrm{E}, \mathrm{Al}_{2} \mathrm{O}_{3} \sim 1 \times$ $\mathrm{BSE}$ ) and models significantly enriched compared to the bulk silicate Earth. As seen in Fig. 1, all estimates, except (Dauphas et al., 2014; Longhi, 2006), of FeO concentration in the Moon lie within the range $11 \leq$ $C(\mathrm{FeO}) \leq 14$ wt $\%$.

Inversion based on the Markov chain Monte Carlo algorithm enabled the evaluation of the bulk concentrations of oxides in the bulk silicate Moon. Figure 3 shows estimated bulk $\mathrm{FeO}$ concentrations (Kronrod et al., 2018); and analogous estimates have been done for $\mathrm{Al}_{2} \mathrm{O}_{3}$.

In both BSM models, the average values of geochemical parameters of the BSM composition are assumed as observed values in calculating the likelihood function (Kronrod et al., 2018):

$$
\begin{gathered}
C_{\mathrm{E}}\left(\mathrm{Al}_{2} \mathrm{O}_{3}\right)=4.05 \pm 0.36 \%, \\
C_{\mathrm{M}}\left(\mathrm{Al}_{2} \mathrm{O}_{3}\right)=5.91 \pm 0.39 \% \\
C_{\mathrm{E}, \mathrm{M}}(\mathrm{FeO})=12.25 \pm 1.33 \text { wt } \% .
\end{gathered}
$$




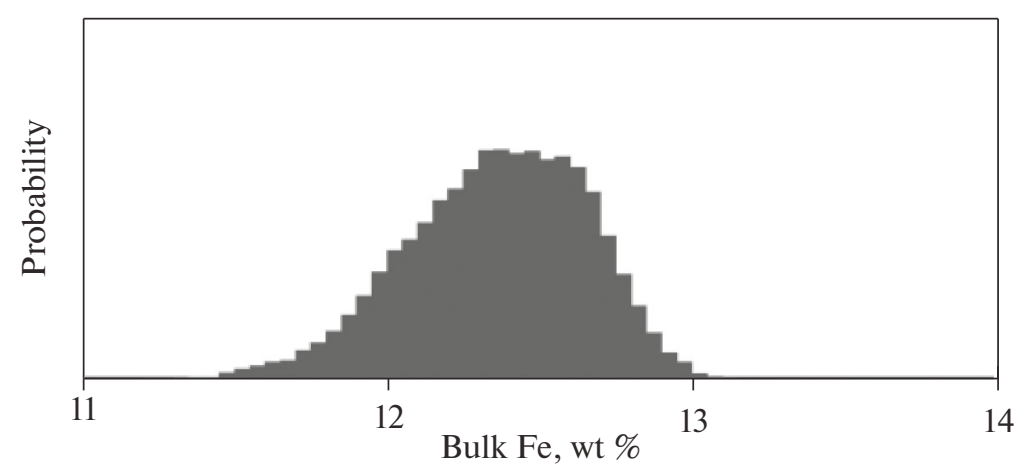

Fig. 3. Posterior probability distribution of the bulk $\mathrm{FeO}$ concentrations in the silicate Moon (crust + mantle).

Oxide concentrations in the upper, middle, and lower mantle, as approximated by the NaTiCFMAS system, were varied with $1 \%$ increments within the following ranges (in wt \%):

$$
\begin{gathered}
25 \leq \mathrm{MgO} \leq 45 \%, 40 \leq \mathrm{SiO}_{2} \leq 55 \%, \\
5 \leq \mathrm{FeO} \leq 15 \%, \quad 0.1 \leq \mathrm{CaO}, \mathrm{Al}_{2} \mathrm{O}_{3} \leq 7 \%,
\end{gathered}
$$

with the $\mathrm{Al}_{2} \mathrm{O}_{3}$ and $\mathrm{CaO}$ concentrations interrelated through the chondrite dependence $\mathrm{CaO} \sim 0.8 \mathrm{Al}_{2} \mathrm{O}_{3}$ (Ringwood, 1977), and the concentrations of other oxides were assumed to be constant: 0.05 wt $\%$ for $\mathrm{Na}_{2} \mathrm{O}$ and $0.2 \mathrm{wt} \%$ for $\mathrm{TiO}_{2}$ (Snyder et al., 1992).

It is pertinent to mention that variations in the concentrations $C(\mathrm{FeO})$ and $C\left(\mathrm{Al}_{2} \mathrm{O}_{3}\right)$ complicatedly affect the physical properties, for example, because the shear modulus of a rock depends on its $\mathrm{FeO}$ content. For instance, an increase in $C(\mathrm{FeO})$ and decrease in $C\left(\mathrm{Al}_{2} \mathrm{O}_{3}\right)$ result in a decrease in the velocities of the seismic waves but can counterbalance the change in the density (Kuskov et al., 2011). An increase in $C(\mathrm{FeO})$ leads to a decrease in the shear modulus and $V_{\mathrm{S}}$ and an increase in the density of the rock. An increase in $C\left(\mathrm{Al}_{2} \mathrm{O}_{3}\right)$ changes the phase proportions and increases the content of garnet, whose density and shear modulus are higher than those of olivine and pyroxene. A simultaneous increase in $C(\mathrm{FeO})$ and $C\left(\mathrm{Al}_{2} \mathrm{O}_{3}\right)$ compensates the changes in the velocities because of a decrease in the shear moduli of minerals, the increase in the garnet content, and the increase in the rock density. Hence, variations in $C(\mathrm{FeO})$ and composition from material depleted in refractory elements to more fertile material nontrivially affects the seismic properties and density of the rock. Moreover, fertilization is associated with changes in the phase proportions, for example, a decrease in the content of orthopyroxene and an increase in the garnet content.

Transition layer. The occurrence of a transition layer at the boundary between the solid mantle and liquid outer core is questioned. Analysis of the Moon's laser ranging has shown that the dissipative losses related to the rotation of the Moon may be induced by interaction at the topographic boundary between the solid mantle and liquid core. This also indirectly follows from selenophysical and electromagnetic data and from seismic wave attenuation in the bottom part of the lower mantle (Nakamura, 2005; Khan et al., 2014; Williams et al., 2001; Williams et al., 2014), as well as from the reanalysis of seismic data (Weber et al., 2011). The presence of a layer of elevated dissipation in the bottom portion of the mantle is consistent with the frequency dependence of the $Q$ factors (Williams et al., 2014; Matsumoto et al., 2015; Harada et al., 2014), although some Moon models can be devoid of LVZ (Garcia et al., 2011; Matsuyama et al., 2016; Karato et al., 2013). The formulation of the problem involves a layer of low viscosity, and the thickness of this layer and its physical properties are found by solving the inverse problem; and the viscosity is calculated according to (Harada et al., 2014; Matsumoto et al., 2015).

Core. Although results of the Apollo experiments and their mathematical processing gave rise to a number of seismic models of the Moon, they are not able to provide direct information on the presence of a core (Lognonné, 2005). Later data, which were based on the consistencies in the stacks of data of different type, suggest that the Moon possesses a solid inner core and a liquid outer one, which is overlain by a partially molten layer, whose thicknesses is evaluated accurate to a few dozen kilometers (Weber et al., 2011; Khan et al., 2014). Because the foci of the deepest moonquakes occur at a depth of $\sim 1200 \mathrm{~km}$, the radius of the core shall not exceed $500 \mathrm{~km}$ (Weber et al., 2011; Garcia et al., 2011). Although the presence of a metallic core $200-400 \mathrm{~km}$ in radius is compatible with geophysical data, such light elements as sulfur, carbon, and silicon, which decrease the density and melting temperature of liquid iron, may have been brought into the core as a consequence of accretion and differentiation of LMO. It is assumed here that the Moon's core consists of an outer liquid core (with a shear modulus $\mu=0 \mathrm{~Pa}$ and viscosity of $0 \mathrm{~Pa} \mathrm{~s}$ ) and a solid inner core, whose seismic properties $\left(V_{P}\right.$ and $\left.V_{S}\right)$ still have to be evaluated. The average density of the inner Fe core or Fe core, which contains a low $S$ concentration, is $\rho=7500 \mathrm{~kg} / \mathrm{m}^{3}$, according to (Kuskov and Belashchenko, 2016). The 
density of the outer liquid core is found by solving the inverse problem.

Inversion, solution technique. Determining parameters of the inner structure of the Moon, which was differentiated as a result of the partial melting of the originally homogeneous body, is based on the joint inversion of the aforementioned geochemical, gravitational, and seismic constraints with regard to materialbalance relations. The problem is solved with the application of the Markov chain Monte Carlo (MCMC) algorithm (Khan et al., 2007; Matsumoto et al., 2015; Kronrod et al., 2018) in combination with minimization of the Gibbs free energy and the MieGrüneisen-Debye equation (Kuskov et al., 1983; Kuskov and Kronrod, 2009) to calculate the equilibrium composition of the mineral assemblages and physical properties of the mantle within the framework of the NaTiCFMAS system, using the THERMOSEISM database, with regard to phase transitions and anharmonicity. The assumed independent components are oxides in the anhydrous NaTiCFMAS system, which form phases of constant and variable composition (Kuskov et al., 2014; Kuskov et al., 1989). Elements whose concentrations are low are ignored. Bivalent iron is assumed to be the dominant mode of iron occurrence in the Moon's mantle, because reducing conditions in the lunar interiors occur at oxygen fugacity close to or below the IW buffer (Wieczorek et al., 2006; Rai and van Westrenen, 2014).

As was mentioned above, some parameters were assumed to be constant: these are the chemical composition and physical properties of the crust, the temperature and thickness of the upper and middle mantle, the density of the inner core, the viscosity of the solid layers, and the bulk $\mathrm{Na}_{2} \mathrm{O}$ and $\mathrm{TiO}_{2}$ concentrations. The $\mathrm{SiO}_{2}$ concentration is not a parameter because the NaTiCFMAS system is normalized to $100 \%$. Concentrations of oxides in the lower mantle are calculated from material-balance relations. The overall number of parameters to be evaluated is fourteen: $\mathrm{Al}_{2} \mathrm{O}_{3}, \mathrm{FeO}$, and $\mathrm{MgO}$ concentrations in the differentiated mantle layers (they are equal in all of the three upper mantle layers, Mantle 1-3), the thickness of LVZ, the radii of the outer and inner core, the density, and bulk and shear moduli of LVZ, inner and outer core (except the shear modulus of the liquid outer core and the density of the inner core), and the viscosity of LVZ.

Concentrations of major oxides in the upper mantle layers are parameters of the model and are used (at each iteration in the chain) to calculate (with the THERMOSEISM program complex) the elastic parameters (the densities and the bulk and shear moduli), which are, in turn, involved in the calculations of the travel time and eventually in the calculations of the likelihood function (LHF). In this formulation, the latter is written in the form (Matsumoto et al., 2015; Kronrod et al., 2018):

GEOCHEMISTRY INTERNATIONAL Vol.59 No. 11

$$
\begin{gathered}
L(m) \propto \exp \left(-\frac{\left(d_{\text {obs }}^{\text {mass }}-d_{\text {cal }}^{\text {mass }}(m)\right)^{2}}{2 \sigma_{\text {mass }}^{2}}\right. \\
\left.-\frac{\left(d_{\text {obs }}^{\text {MOI }}-d_{c a l}^{M O I}(m)\right)^{2}}{2 \sigma_{M O I}^{2}}-\frac{\left(d_{o b s}^{k 2}-d_{c a l}^{k 2}(m)\right)^{2}}{2 \sigma_{k 2}^{2}}\right) \\
\times \exp \left(-\frac{\left(d_{o b s}^{Q a}-d_{c a l}^{Q a}(m)\right)^{2}}{2 \sigma_{Q a}^{2}}-\frac{\left(d_{\text {obs }}^{Q m}-d_{c a l}^{Q m}(m)\right)^{2}}{2 \sigma_{Q m}^{2}}\right. \\
\times \exp \left(-\frac{\left(d_{\text {obs }}^{\text {Albulk }}-d_{\text {cal }}^{\text {Albulk }}(m)\right)^{2}}{2 \sigma_{\text {Albulk }}^{2}}-\frac{\left(d_{\text {obs }}^{\text {Febulk }}-d_{\text {cal }}^{\text {Fe bulk }}(m)\right)^{2}}{2 \sigma_{\text {Febulk }}^{2}}\right),
\end{gathered}
$$

where $d_{\text {obs }}, d_{\text {cal(m) }}, \sigma$, and $\tau_{\mathrm{n}}$ denote the observed data and those calculated by model $\mathrm{m}$, the uncertainties of the observed data and the $n$th travel time of seismic waves, respectively. The bulk $\mathrm{Al}_{2} \mathrm{O}_{3}$ and $\mathrm{FeO}$ concentrations are denoted $\left(A l_{\text {bulk }}\right)$ and $\left(F e_{\text {bulk }}\right)$.

The likelihood function show how much the theoretical values deviate from the observed ones with regard to that the difference between the calculated and experimentally determined values is no greater than the specified error. The solution for the required parameters is determined from their a posteriori distribution. The space of the parameters was tested by $21 \times$ $10^{6}$ MCMC iterations with ten parallel chains. The length of each chain was three million, with the first $30 \%$ of the samples rejected at processing. The inversion yields a probable model for the Moon that is best (in a sense) consistent with the set of geophysical and geochemical constraints.

\section{RESULTS AND DISCUSSION}

The problem is formulated as follows: at specified selenophysical, seismic, and geochemical conditions for the model of the inner structure of the Moon, which were selected as observed values for calculating the likelihood functions, the model yields the chemical composition of the mantle, physical properties (velocities of $P$ - and $S$-waves and densities) of the mantle and central region, the thickness of the transition layer, and the sizes of the $\mathrm{Fe}-\mathrm{S}$ core. All of the aforementioned parameters are determined by solving an inverse problem at geochemical constraints placed on the bulk composition $C_{\mathrm{E}, \mathrm{M}}\left(\mathrm{Al}_{2} \mathrm{O}_{3}\right)$ and $C_{\mathrm{E}, \mathrm{M}}(\mathrm{FeO})$ according to (3) within the concentration ranges (4), with regard to constraints (2) on the temperature distribution. 

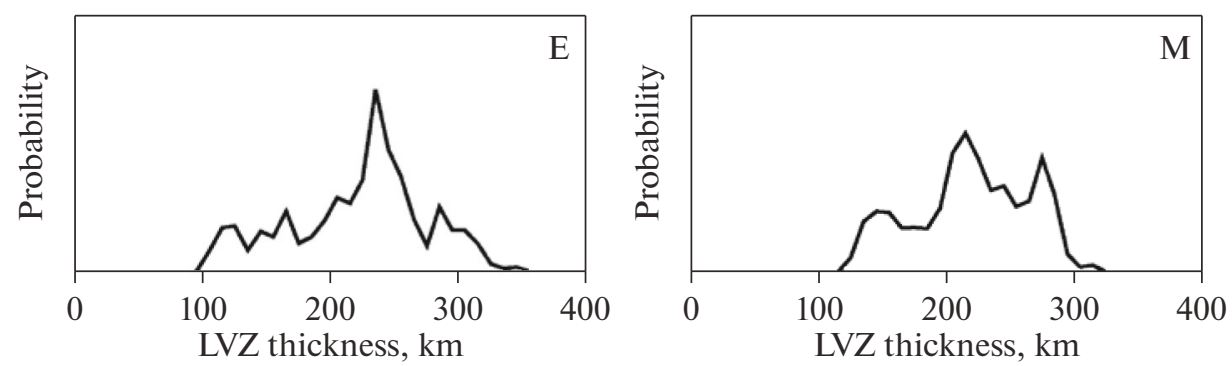

Fig. 4. Inversion results for evaluating the $\mathrm{LVZ}$ thickness used in geochemical models $\mathrm{E}$ and $\mathrm{M}$ with a triple error $\sigma_{\tau \mathrm{n}}=3 \sigma_{\tau \mathrm{nL}}$ of the travel time of seismic waves according to (Lognonné et al., 2003).

\section{Mantle}

Concentrations of $\mathrm{FeO}$ in all successful $\mathrm{E}$ and $\mathrm{M}$ models in all mantle zones and in the silicate Moon (crust + mantle) are almost constant: $12-13$ wt $\%$. The narrow range of the $\mathrm{FeO}$ concentrations is consistent with earlier results (Kuskov and Kronrod, 2000; Lognonné et al., 2003; Khan et al., 2007; Sakai et al., 2014; Kronrod et al., 2019; Kuskov et al., 2019a, $2019 \mathrm{~b}$ ), which indicates that the results of the inversion of geophysical data in terms of chemical composition are robust. Conversely, geochemical and cosmochcemical estimates of BSM are broadly scattered: from 7.6\% FeO (Longhi, 2006) to 13-14\% FeO (Morgan et al., 1978; Taylor et al., 2006).

$\mathrm{SiO}_{2}$ concentrations in all zones of the Moon's mantle vary insignificantly and are $52-53 \mathrm{wt} \%$ in models $\mathrm{E}$ and $\mathrm{M}$. Much $\mathrm{SiO}_{2}$, and hence, a high pyroxene content, are geochemical implications of the inversion of geophysical data. The most reliable result was obtained for the upper mantle consisting mostly of olivine-bearing pyroxenite, whose dominant mineral is low-Ca pyroxene but not olivine. This result is compatible with the inversion of Apollo seismic data (Lognonné et al., 2003; Khan et al., 2006; Kuskov et al., 2019a, 2019b) and with petrological (Ringwood and Essene 1970; Moriarty et al., 2021) and spectral observation according to data of the Kaguya and Chang'E missions ( $\mathrm{Li}$ et al., 2019; Lemelin et al., 2019).

Conversely, the mantle is stratified in terms of $\mathrm{Al}_{2} \mathrm{O}_{3}$, with a higher concentration of this component in the lower mantle (= BSM) than in the overlying shells (Kronrod et al., 2019). For model E, $C_{\mathrm{E}}\left(\mathrm{Al}_{2} \mathrm{O}_{3}\right)_{\text {low mantle }}=C_{\mathrm{E}}\left(\mathrm{Al}_{2} \mathrm{O}_{3}\right)_{\text {bulk }} \sim 4.2$ wt $\%\left(\mathrm{Al}_{2} \mathrm{O}_{3} \sim\right.$ $1 \times \mathrm{BSE}$ ), which is close to the estimates in (Khan et al., 2007; Kronrod and Kuskov, 2011). For model M, $C_{\mathrm{M}}\left(\mathrm{Al}_{2} \mathrm{O}_{3}\right)_{\text {low mantle }}=C_{\mathrm{M}}\left(\mathrm{Al}_{2} \mathrm{O}_{3}\right)_{\text {bulk }} \sim 5.6 \mathrm{wt} \%\left(\mathrm{Al}_{2} \mathrm{O}_{3} \sim\right.$ $1.4 \times \mathrm{BSE}$ ), which is close to the estimates in (Lognonné et al., 2003; Kuskov et al., 2019a, 2019b). Content of garnet of the approximate composition $P y_{70} \mathrm{Al}_{25} \mathrm{Gr}_{5}$ in the lower mantle may be as high as $10 \%$ in model $\mathrm{E}$ and up to $15 \%$ in model $\mathrm{M}$.

\section{Transition Layer}

The thickness and physical parameters of the partially molten layer of low viscosity or rigidity according to geochemical models $\mathrm{E}$ and $\mathrm{M}$ are shown in Figs. 4 and 5. The differences in the chemical/mineralogical composition and, hence, in the density of the mantle in models $\mathrm{E}$ and $\mathrm{M}$ are obviously small and only insignificantly affect parameters of LVZ. The LVZ region approximately $200-250 \mathrm{~km}$ thick (Fig. 4) occurs at depths of $\sim 1200$ to $\sim 1400 \mathrm{~km}$. It is hard to further constrain the range of the values because the thickness of LVZ may be negatively correlated with the outer core radius (Matsumoto et al., 2015). Current estimates of the LVZ thickness lie within the range of 150-200 km (Weber et al., 2011; Khan et al., 2014).

Parameters of the LVZ layer (its thickness, viscosity, density, and elastic moduli) were varied within broad limits. Most of the successful solutions do involve a LVZ layer, although the simulated distributions of physical properties of LVZ (Fig. 5) are far from normal and broadly vary. For both $\mathrm{E}$ and $\mathrm{M}$ models, the probable seismic wave velocities lie within the range of 7.3$8 \mathrm{~km} / \mathrm{s}$ for $V_{\mathrm{P}}$ and 3-3.5 km/s for $V_{\mathrm{S}}$ (Fig. 5), which is in reasonably good agreement with (Weber et al., 2011; Matsumoto et al., 2015). According to data in (Williams et al., 2014), $V_{\mathrm{P}}=7.16 \mathrm{~km} / \mathrm{s}$ and $V_{\mathrm{S}}=2.7 \mathrm{~km} / \mathrm{s}$.

Based on interpretations of data on the Moon's laser ranging and the Apollo and GRAIL experiments (Williams et al., 2001, 2014; Weber et al., 2011; Harada et al., 2014), some researchers suggest that a partly molten layer occurs above the liquid core. The presence of such a layer is consistent with the moment of inertia, tidal Love number, and Q factor. Matsumoto et al. (2015) have found out that the occurrence of a low-velocity zone more than $170 \mathrm{~km}$ thick is required for consistency with the observation data. The potentially possible presence of a zone of higher dissipation in the bottom of the mantle, at its boundary with the core, follows from interpretations of geophysical data (Khan et al., 2014). Our data (Fig. 5) suggest that a transition layer $L^{\prime \prime}$ shall be present in the bottom part of the Moon's mantle, which is characterized by a low $V_{\mathrm{S}}$. Williams et al. (2014) also believe that this zone has 

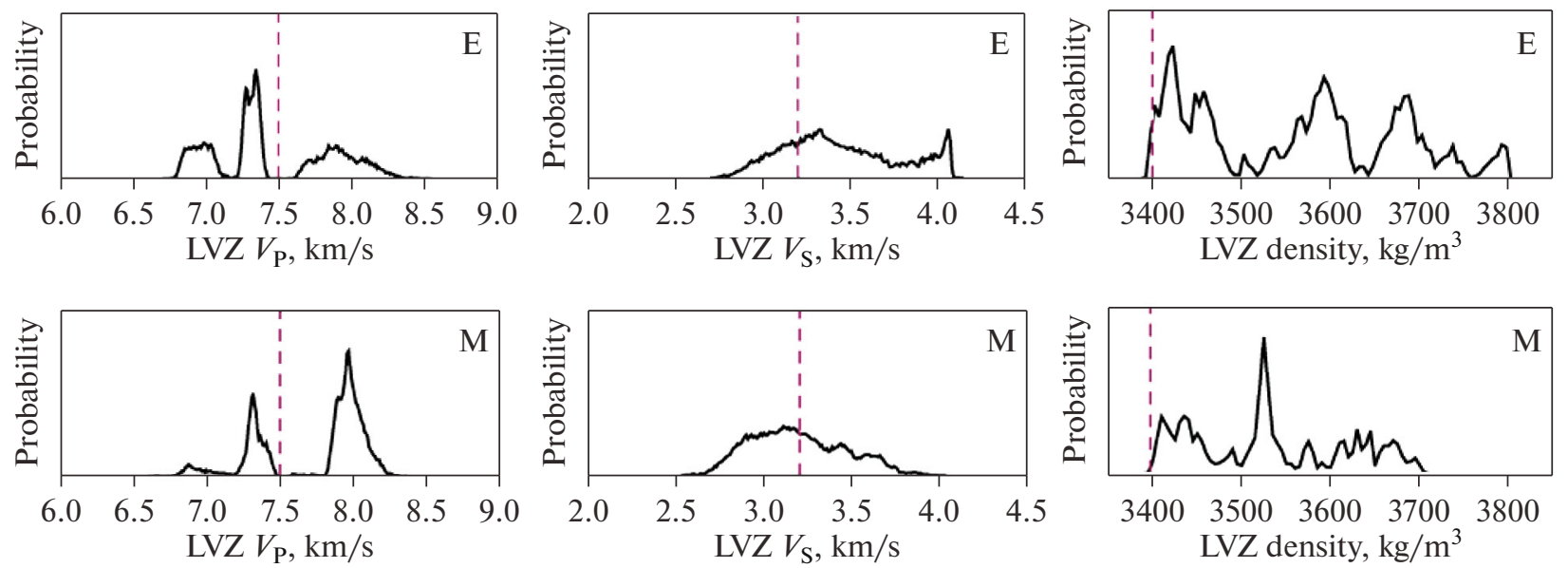

Fig. 5. 2D Posterior probability distribution derived with the inversion of seismic, selenophysical, and geochemical (models $\mathrm{E}$ and $\mathrm{M}$ ) constraints on the distribution of $P$ - and $S$-wave velocities and density in the transition layer, with a triple error of the travel time $\sigma_{\tau \mathrm{n}}=3 \sigma_{\tau \mathrm{nL}}$. Vertical dashed lines show the values of the model (Weber et al., 2011).

low $V_{\mathrm{S}}$, whereas Harada et al. (2014) hypothesize that a superlow viscosity may occur in the bottom part of the mantle. Based on the joint inversion of seismic and gravity data, Raevskiy et al. (2015) have determined that the model and experimentally estimated Love numbers can be made consistent by assuming that shear modulus may be lower in the bottom of the mantle, which can be interpreted as the occurrence of a partial melting zone of mantle material in the vicinities of the core.

Conversely, Nimmo et al. (2012) suggest that a viscoelastic dissipative layer without melting may occur in the bottom of the mantle. Matsuyama et al. (2016) have constrained the density of the transition layer within 3500 to $5090 \mathrm{~kg} / \mathrm{m}^{3}$ but thought that observation data are still insufficient to demonstrate either the presence or the absence of a transition layer. Karato et al. (2013) have arrived at the conclusion that partial melting is hardly possible, and Garcia et al. (2011) have not identified layer $L^{\prime \prime}$ at all.

The density of LVZ is of crucial importance for understanding the stability of the layer, i.e., whether this layer is characterized by positive, negative, or neutral buoyancy with respect to the bulk density in models $\mathrm{E}$ and $\mathrm{M}$. The inversion results show that the density of LVZ layer (Fig. 5) is higher than $3400 \mathrm{~kg} / \mathrm{m}^{3}$, which is in reasonably good agreement with geophysical data (Matsumoto et al., 2015; Weber et al., 2011; Khan et al., 2014). For geochemical models E and M, mantle density values at depths from $750 \mathrm{~km}$ to the LVZ boundary are varied from $3398 \mathrm{~kg} / \mathrm{m}^{3}$ for models E to $3409 \mathrm{~kg} / \mathrm{m}^{3}$ for models $M$ and are close to the lower limit for the LVZ density (Fig. 5), which is in good agreement with experimental results (van Kan Parker et al., 2012) and shows that the melts of lunar black glasses that contain $\sim 16 \mathrm{wt} \% \mathrm{TiO}_{2}$ and have a density of about $3400 \mathrm{~kg} / \mathrm{m}^{3}$ are characterized by neu- tral buoyancy at the mantle-core boundary. Khan et al. (2014) have also arrived at the conclusion that the Moon's deep interiors shall involve a partly molten layer $150-200 \mathrm{~km}$ thick, which is enriched in $\mathrm{FeO}$ and $\mathrm{TiO}_{2}$ and has a density of $3250-3450 \mathrm{~kg} / \mathrm{m}^{3}$, as is typical of lunar magmas with moderate and high $\mathrm{TiO}_{2}$ concentrations $\left(<15 \mathrm{wt} \% \mathrm{TiO}_{2}\right)$. The occurrence of such partly molten material, which is enriched in radioactive elements, prevents core cooling and maintains the outer part of the core in a liquid state, as follows from analysis of LLR data (Williams et al., 2001).

\section{Core}

Results of inversion aimed at determining parameters of the Moon's core are shown in Fig. 6. For models $\mathrm{E}$ and $\mathrm{M}$, the radius and density of the liquid outer core $\left(R_{\mathrm{oc}}\right.$ and $\left.\rho_{\mathrm{oc}}\right)$ are presented, along with the radius of the solid inner core $\left(R_{\mathrm{ic}}\right)$, at a constant density $\rho_{\mathrm{ic}}=$ $7500 \mathrm{~kg} / \mathrm{m}^{3}$. Evidently, neither the differences in composition nor those in the density between models $\mathrm{E}$ and $M$ only insignificantly affect parameters of the core. This is explained by that the physical properties of the mantle were determined in models $E$ and $M$ from consistency with available data on the travel times of $P$ - and $S$-waves in the mantle only to a depth of $\sim 1200 \mathrm{~km}$ (Lognonné et al., 2003; Weber et al., 2011), because seismic sources for greater depths are absent.

In both model $\mathrm{E}$ and $\mathrm{M}$, the probable radii of the outer core $R_{\mathrm{oc}} \sim 300-350 \mathrm{~km}$ (Fig. 6) are consistent with processed experimental Apollo data $R_{\mathrm{oc}}=330 \pm 20$ (Weber et al., 2011) and $R_{\mathrm{oc}}=380 \pm 40 \mathrm{~km}$ (Garcia et al., 2011). The density and speed of sound in the outer core are $\rho=4500-7500 \mathrm{~kg} / \mathrm{m}^{3}$ and $V_{P}=4000-$ $5000 \mathrm{~m} / \mathrm{s}$, with these values lying within the inversion range (Matsumoto et al., 2015). The radii of the solid 

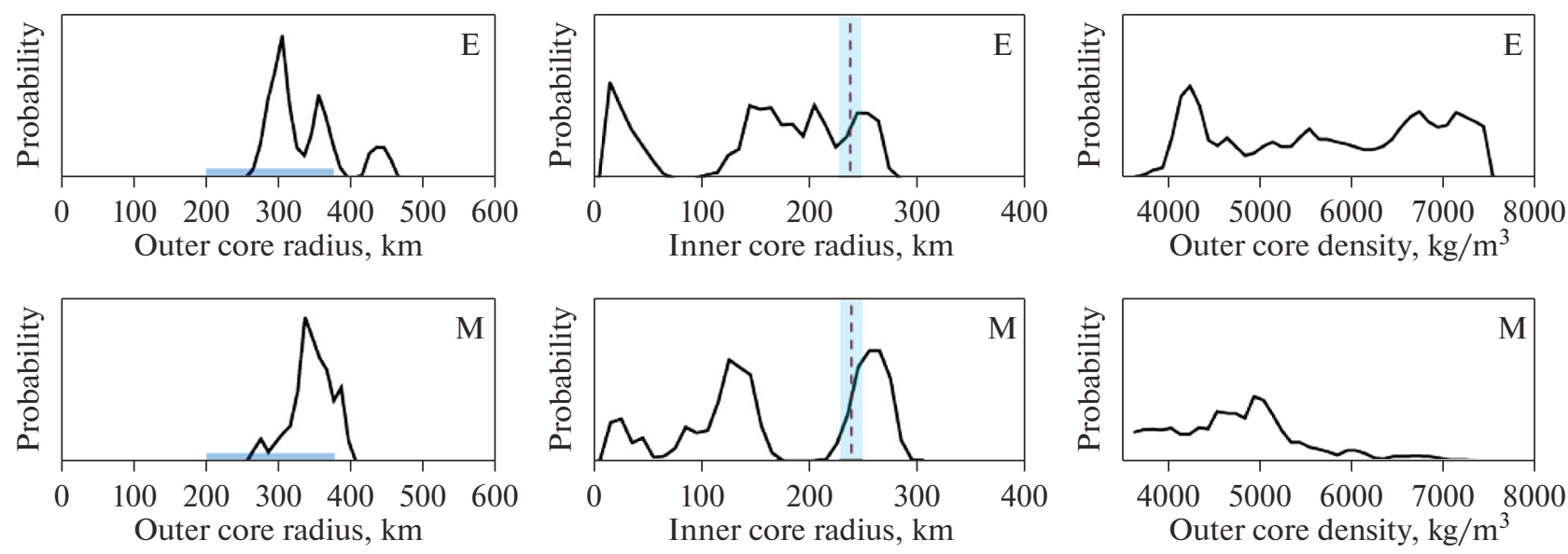

Fig. 6. Posterior probability distribution derived with the inversion of seismic $\left(\sigma_{\tau \mathrm{n}}=3 \sigma_{\tau \mathrm{nL}}\right)$ and selenophysical constraints and geochemical models $\mathrm{E}$ and $\mathrm{M}$ for the radii and density of the outer fluid core and the radii of the inner solid core. Horizontal bars for models $\mathrm{E}$ and $\mathrm{M}$ shows the sizes of the core according to data of GRAIL (Williams et al., 2014) and Apollo (Weber et al., 2011; Garcia et al., 2011); vertical dashed lines with shading show the values of the model (Weber et al., 2011). The average density of the inner Fe core or the Fe core with a low concentration of a light element $\rho=7500 \mathrm{~kg} / \mathrm{m}^{3}$ is assumed according to (Kuskov and Belashchenko, 2016).

inner core, whose presence does not directly follow from seismic and selenophysical data, are $R_{\mathrm{ic}} \sim 50-$ $250 \mathrm{~km}$ (Fig. 6). According to models based on GRAIL and Apollo data (Weber et al., 2011; Williams et al., 2014), the fluid core has $R_{\mathrm{oc}}=200-380 \mathrm{~km}$, and the solid inner core has $R_{\mathrm{ic}}=0-280 \mathrm{~km}$. Indicating that the inner structure of the core is heterogeneous, these data make it possible to place constraints onto the sizes of the outer and inner core but do not allow one to reasonably reliably evaluate their densities.

Because of this, the density of the outer core, which depends on the composition, temperature, and pressure, is still a poorly constrained parameter, which is to be refined based on other considerations. Although experimental data on the physical properties of $\mathrm{Fe}$ based alloys under $P-T$ parameters of the Moon's core are still relatively scarce, it is useful to compare them with the seismic estimates. The results of experiments on measuring the density and the speed of sound in Fe melts and the effect of the thermal state on the size of the Moon's core are presented in Figs. 7-9.

Figure 7 displays histograms for the radius of the liquid $\mathrm{Fe}-\mathrm{S}$ core, containing 3.5-6 wt $\% \mathrm{~S}$, in the form of frequency distributions whose average values correspond to solutions that satisfy the specified constraints of the thickness and density of the crust, the mass and moment of inertia of the Moon, the velocities of $P$ - and $S$-waves in the mantle, and constraints on the chemical composition of the mantle, its mineralogy, and density (Kuskov et al., 2019b). The density of the $\mathrm{Fe}-\mathrm{S}$ melt was calculated by techniques of molecular dynamics (Kuskov and Belashchenko, 2016). As seen in Fig. 7, the sizes of the core relatively weakly depend on the thermal regime and correspond to a range of $250-350 \mathrm{~km}$, which is in very good agree- ment with the results of inversion of the seismic and selenophysical data (Fig. 6).

Table 1 presents models for the Moon's core, which were derived from gravitational, electromagnetic, and seismic data and are compared with theoretical estimates based on the joint inversion of data on the velocities of seismic waves and on the Moon's mass and moment of inertia. It can be seen that the core radius depends on its composition (density) and on interpretations of seismic and selenophysical data.

It may be seemed that data in Table 1 on the radii and densities of the core are reasonably well consistent (within the errors) with one another. However, this consistence is not as obvious because the composition of the core is unknown, and its density under $P-T$ parameters of the central region $(5 \pm 0.5 \mathrm{GPa}$ and 1800-2000 K) may broadly vary.

In seismological papers (Weber et al., 2011; Garcia et al., 2011), the density of the outer core is assumed to be $\rho=5.1-5.2 \mathrm{~g} / \mathrm{cm}^{3}$, which corresponds to the density of FeS alloy at $4.5 \mathrm{GPa}$ and $1650 \mathrm{~K}$ (Chen et al., 2014) but is much lower than the densities of bcc-Fe, fcc-Fe, and liquid $\mathrm{Fe}-\mathrm{S}-\mathrm{C}-\mathrm{Si}$ alloys under high pressures (Tsujino et al., 2013; Dorogokupets et al., 2014; Antonangeli et al., 2015; Nishida et al., 2016). A density of the outer core close to $5 \mathrm{~g} / \mathrm{cm}^{3}$ (Chen et al., 2014 ) is reached only at a sulfur concentration of 50 at \%, which is much higher than the sulfur abundances in meteorites (Jarosewich, 1990). This discussion implies that the density of the Moon's outer core in the seismic model does not correspond to experimental measurements of the density of liquid Fe alloys under high pressures.

Figure 8 presents experimental data on the density of $\mathrm{Fe}-\mathrm{S}$ alloys, which indicate that these values vary 

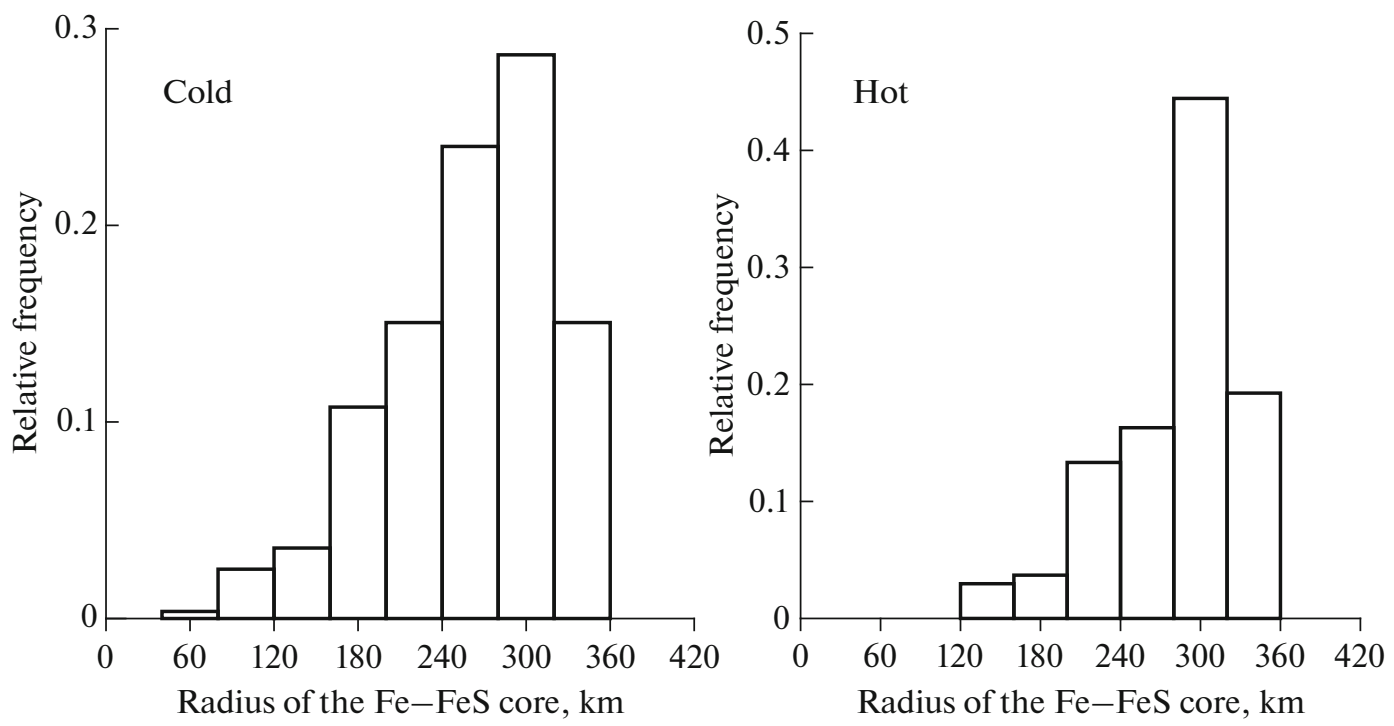

Fig. 7. Histograms for the radii of the $\mathrm{Fe}-\mathrm{S}$ core of average density of $7.1 \mathrm{~g} / \mathrm{cm}^{3}$ and containing $6-10$ at $\% \mathrm{~S}(3.5-6$ wt $\%)$ for two models of the thermal state of the Moon. The calculations were carried out for two temperature profiles at the depths of the middle of the mantle reservoirs (in km): the cold model $T_{150}=600^{\circ} \mathrm{C}, T_{500}=900^{\circ} \mathrm{C}, T_{1000}=1100^{\circ} \mathrm{C}$ and the hot $\operatorname{model} T_{150}=700^{\circ} \mathrm{C}$, $T_{500}=1100^{\circ} \mathrm{C}, T_{1000}=1300^{\circ} \mathrm{C}$ (according to Kuskov et al., 2019b).

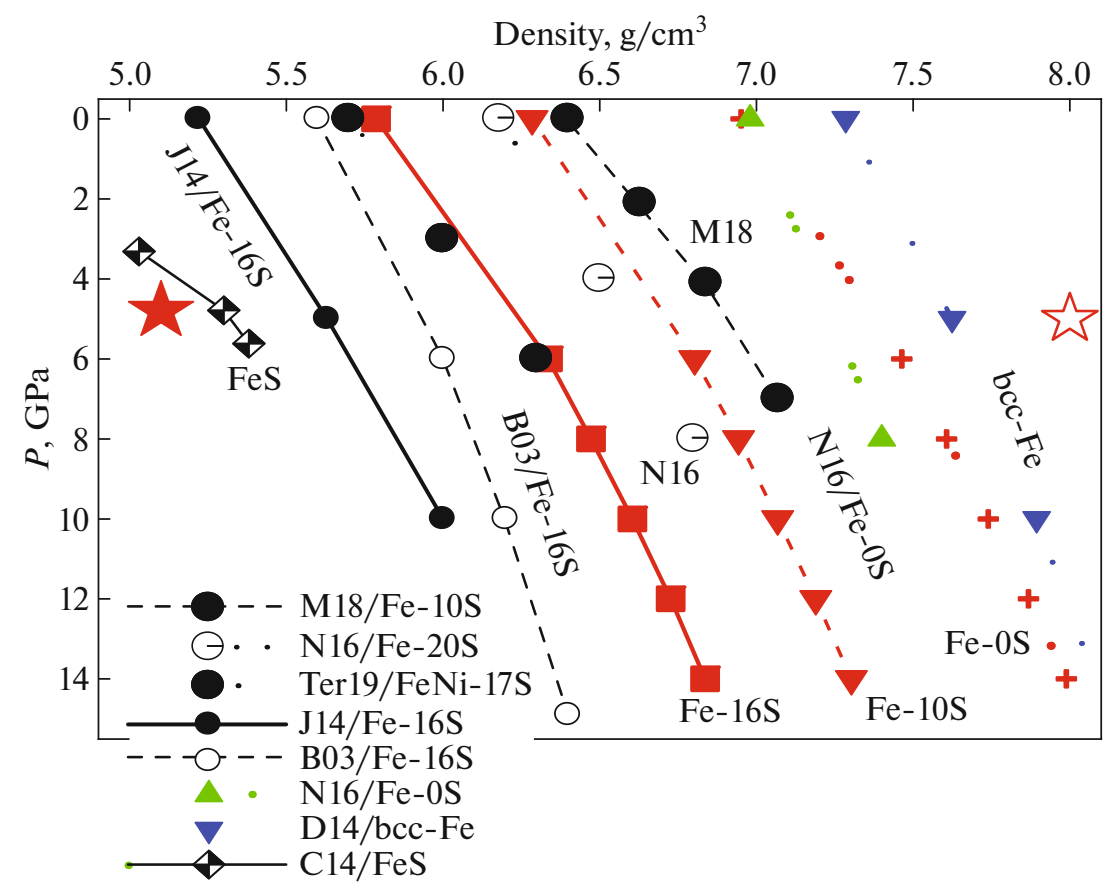

Fig. 8. Densities of $\mathrm{Fe}(\mathrm{Ni})-\mathrm{S}$ melts (all concentrations are given in at \%) in comparison with the model density of the Moon's core. The open and solid stars are the densities of the solid inner $\left(\rho=8 \mathrm{~g} / \mathrm{cm}^{3}\right)$ and liquid outer $\left(\rho=5.1 \mathrm{~g} / \mathrm{cm}^{3}\right)$ core according to (Weber et al., 2011). Experiments: $M 18=$ Morard et al. (2018), Fe-10 at \% S (6 wt \% S) / $1900 \mathrm{~K}$; N16 = Nishida et al. (2016), $\mathrm{Fe}-0 \% \mathrm{~S}$ (pure Fe), Fe-20 at \% S (13 wt \% S) / $1923 \mathrm{~K}$; Ter19= Terasaki et al. (2019), $\mathrm{Fe}_{73} \mathrm{Ni}_{10} \mathrm{~S}_{17}$ (10 wt \% S) / $1900-2000 \mathrm{~K}$; $\mathrm{J} 14=$ Jing et al. (2014), Fe-16 at \% S (10 wt \% S) / $1923 \mathrm{~K}$; B03 = Balog et al. (2003), Fe-16 at \% S (10 wt \% S) / 1773-2123 K; D14 = Dorogokupets et al. (2014), bcc-Fe / $1811 \mathrm{~K}$; C14 = Chen et al. (2014), FeS melt/1650 K. 


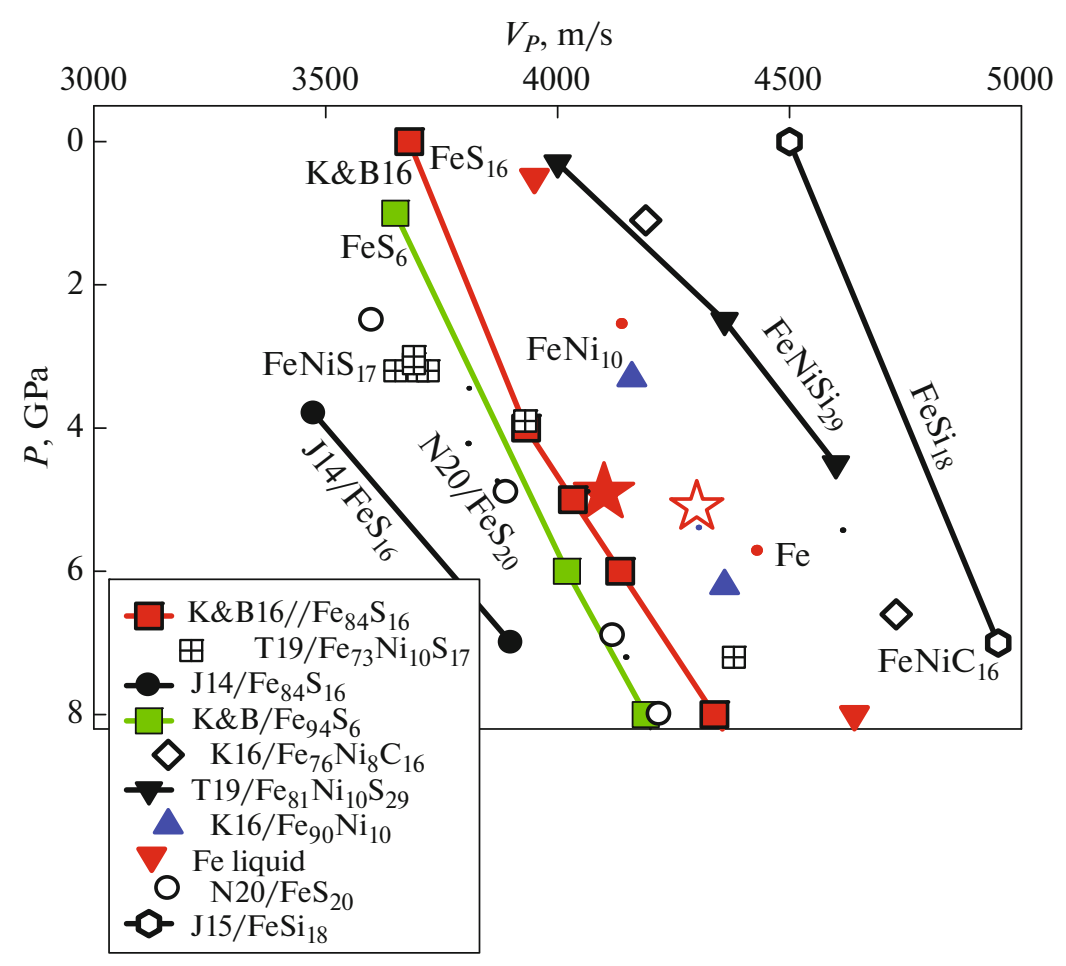

Fig. 9. Comparison of the speed of sound $\left(V_{P}\right)$ of $\mathrm{Fe}(\mathrm{Ni})-\mathrm{S}-\mathrm{C}-\mathrm{Si}$ liquids (all concentrations are given in at \%) with Apollo seismic data $V_{P}=4100 \mathrm{~m} / \mathrm{s}$ for the outer (solid star) and $V_{P}=4300 \mathrm{~m} / \mathrm{s}$ for the inner (open star) Moon's core, according to the model (Weber et al., 2011). The $V_{P}$ values of ultrasonic experiments at $1700-2000 \mathrm{~K}$ are according to: J14 $=\mathrm{Jing}$ et al. $(2014)$, Fe ${ }_{84} \mathrm{~S}_{16}$ (10 wt \% S); N20 = Nishida et al. (2020), $\mathrm{Fe}_{80} \mathrm{~S}_{20}(13 \mathrm{wt} \% \mathrm{~S}) ; T 19=$ Terasaki et al. (2019), $\mathrm{Fe}_{73} \mathrm{Ni}_{10} \mathrm{~S}_{17}(10.5 \mathrm{wt} \% \mathrm{~S}) ; \mathrm{T} 19=$ Terasaki et al. (2019), $\mathrm{Fe}_{61} \mathrm{Ni}_{10} \mathrm{Si}_{29}(17 \mathrm{wt} \% \mathrm{Si}) ; \mathrm{K} 16=$ Kuwabara et al. (2016), $\mathrm{Fe}_{75} \mathrm{Ni}_{8} \mathrm{C}_{16.3}(\mathrm{Ni}=10 \mathrm{wt} \%, \mathrm{C}=4 \mathrm{wt} \%)$ and $\mathrm{Fe}_{90.4} \mathrm{Ni}_{9.6}(\mathrm{Ni} \sim 10 \mathrm{wt} \%)$; J15 = Jing et al. (2015), $\mathrm{Fe}_{82} \mathrm{Si}_{18}\left(10 \mathrm{wt} \% \mathrm{Si}\right.$ ). $V_{P}$ for liquid Fe (dotted line) according to (Jing et al., 2014; Nishida et al., 2016, 2020). K\&B16 = Kuskov and Belashchenko (2016), calculations by molecular dynamics techniques for $\mathrm{Fe}-\mathrm{S}$ melt at $2000 \mathrm{~K}$ and $\mathrm{S}$ of 6 at \% (3.5 wt \%) and 16 at \% (10 wt \%).

from $\rho \sim 5 \mathrm{~g} / \mathrm{cm}^{3}$ at $5 \mathrm{GPa}$, which corresponds to the density of liquid iron sulfide (Chen et al., 2014; Nishida et al., 2016) to $6 \mathrm{~g} / \mathrm{cm}^{3}$ for $\mathrm{Fe}-29$ at $\% \mathrm{~S}$ (Morard et al., 2018) and to $6.2-6.9 \mathrm{~g} / \mathrm{cm}^{3}$ for $\mathrm{Fe}-16$ to 10 at \% S (Kuskov and Belashchenko, 2016; Morard et al., 2018; Terasaki et al., 2019). For pure Fe and Fe$10 \% \mathrm{Ni}, \rho \sim 7.2-7.4 \mathrm{~g} / \mathrm{cm}^{3}$ (Jing et al., 2015; Antonangeli et al., 2015; Nishida et al., 2016; Kuskov and Belashchenko, 2016; Kuwabara et al., 2016). At $5 \mathrm{GPa}$, the densities of binary $\mathrm{Fe}-\mathrm{S}$ (up to $\sim 13 \mathrm{wt} \% \mathrm{~S}$ ), $\mathrm{Fe}-\mathrm{C}(3.5 \mathrm{wt} \% \mathrm{C})$, and $\mathrm{Fe}-\mathrm{Si}(10 \mathrm{wt} \% \mathrm{Si})$ and triple liquid alloys $\mathrm{Fe}-\mathrm{C}-\mathrm{Si}(3.6 \mathrm{wt} \% \mathrm{C}$ and $7.2 \mathrm{wt} \% \mathrm{Si}$ ) (Shimoyama et al., 2013; Nishida et al., 2016; Knibbe et al., 2021), $\mathrm{Fe}_{90} \mathrm{Ni}_{10}-3-5$ wt \% C (Zhu et al., 2021) fall within the range of $\rho \sim 6.2-7.2 \mathrm{~g} / \mathrm{cm}^{3}$, which is best consistent with model $\mathrm{E}$ for the density of the outer core (Fig. 6) but is $20-30 \%$ higher than the density of the outer core according to seismic data (Garcia et al., 2011; Weber et al., 2011).

The composition of the Fe-based melt/alloy is important not only as a geochemical characteristic of the core but is also a parameter of critical importance for evaluating its radius, because the size of the core is determined as depending on the density of the mate- rial of this core (Table 1). It follows from laboratory experiments and molecular-dynamics numerical experiments that the average density of the outer core cannot be much higher than $\sim 7.2 \mathrm{~g} / \mathrm{cm}^{3}$ and much lower than $\sim 6.2 \mathrm{~g} / \mathrm{cm}^{3}$ (Fig. 8), which corresponds to liquid $\mathrm{Fe}-\mathrm{Ni}$ alloy with admixtures (no more than $\sim 10 \mathrm{wt} \%$ ) of light elements, although the exact composition is uncertain. Hypothetically, an alternative of the metallic $\mathrm{Fe}-$ $\mathrm{Ni}-\mathrm{S}$ core might be a dense, partly molten silicate core enriched in $\mathrm{FeO}$ and $\mathrm{TiO}_{2}$ and having a high electric conductivity.

A more complicated issue is which light element (or elements) may occur in the lunar core and what are their probable concentrations. Sulfur is a siderophile element and a leading candidate for a light admixture in the core. It has been hypothesized that the depletion of the lunar mantle in siderophile elements may be explained by that sulfur is contained in the core, and variants of sulfur-rich and sulfur-poor core were analyzed (Rai and van Westrenen, 2014; Steenstra et al., 2016; Jing et al., 2014; Antonangeli et al., 2015; Nishida et al., 2016; Morard et al., 2018). Furthermore, Fe sulfides are commonly found in iron meteorites. Other models do not rule out that the core may contain carbon and silicon (Righter et al., 2017; 
Table 1. Models of the Moon's core

\begin{tabular}{|c|c|c|c|c|}
\hline $\begin{array}{l}\text { Composition of the } \\
\text { Moon's outer core }\end{array}$ & $\begin{array}{l}\text { Radius of the Moon's } \\
\text { outer core, } \mathrm{km}\end{array}$ & $\begin{array}{c}\text { Density of the Moon's } \\
\text { outer core, } \mathrm{kg} / \mathrm{m}^{3}\end{array}$ & Method & References \\
\hline $\begin{array}{l}\text { Unknown } \\
\text { Unknown }\end{array}$ & $\begin{array}{l}340 \pm 90 \\
290-400\end{array}$ & $\begin{array}{l}\text { Unknown } \\
\text { Unknown }\end{array}$ & $\begin{array}{l}\text { Lunar Prospector and } \\
\text { Kaguya electromagnetic } \\
\text { data }\end{array}$ & \begin{tabular}{|l} 
Hood et al. (1999) \\
Shimizu et al. (2013)
\end{tabular} \\
\hline $\begin{array}{l}\mathrm{Fe} \\
\mathrm{Fe}-\mathrm{FeS} \text { eutectic }\end{array}$ & $\begin{array}{l}\leq 352 \\
\leq 374\end{array}$ & $\begin{array}{c}\text { Fe density } \\
\mathrm{Fe}-\mathrm{FeS} \text { density }\end{array}$ & $\begin{array}{l}\text { Lunar Laser Ranging, } \\
\text { LLR }\end{array}$ & Williams et al. (2001) \\
\hline$\overline{\mathrm{Fe}}-\leq 6 \mathrm{wt} \% \mathrm{~S}$ & $330 \pm 20$ & 5100 & \multirow[t]{2}{*}{ Apollo data interpretations } & Weber et al. (2011) \\
\hline Unknown & $380 \pm 40$ & 5171 & & Garcia et al. (2011) \\
\hline Unknown & $200-380$ & Unknown & GRAIL mission & Williams et al. (2014) \\
\hline Unknown & $200-410$ & $4700-7500$ & $\begin{array}{l}\text { GRAIL, LLR, and LOLA* } \\
\text { data inversion }\end{array}$ & Matsuyama et al. (2016) \\
\hline Unknown & $\begin{array}{l}220-395 \\
330-380\end{array}$ & $\begin{array}{l}5500-4500 \\
4500-5000\end{array}$ & $\begin{array}{l}\text { Inversion of gravity, seis- } \\
\text { mic, and electromagnetic } \\
\text { data }\left(M, I / M R^{2}, k_{2}, T_{P}, T_{S},\right. \\
\left.Q, \rho_{a}(\omega)\right)\end{array}$ & $\begin{array}{l}\text { Matsumoto et al. (2015) } \\
\text { Khan et al. (2014) } \\
\text { Garcia et al. (2019) }\end{array}$ \\
\hline $\begin{array}{l}\mathrm{Fe}-10 \text { wt } \% \mathrm{~S} \\
\mathrm{Fe}\end{array}$ & $\begin{array}{l}340 \pm 30 \\
290-340\end{array}$ & $\begin{array}{l}5700 \\
8000\end{array}$ & \multirow{2}{*}{\begin{tabular}{|l|} 
Inversion of seismic, sele- \\
nophysical, and geochemi- \\
cal data and $\mathrm{E}$ and $\mathrm{M}$ \\
geochemical models \\
$\left((\mathrm{FeO})_{\text {bulk }}\right),\left(\mathrm{Al}_{2} \mathrm{O}_{3}\right)_{\text {bulk}}$ \\
$\left.M, I / M R^{2}, T_{P}, T_{S}, k_{2}, Q\right)$ \\
with regard to the density \\
of liquid $\mathrm{Fe}(\mathrm{Ni})-\mathrm{S}$ alloys
\end{tabular}} & $\begin{array}{l}\text { Kronrod and Kuskov (2011) } \\
\text { Kuskov and Kronrod, } \\
\text { (2000) }\end{array}$ \\
\hline $\begin{array}{l}\mathrm{Fe}(\mathrm{Ni})-\mathrm{S} \\
\text { (up to } \sim 10 \mathrm{wt} \% \mathrm{~S} \text { ) }\end{array}$ & $300-350$ & $6200-7000$ & & This publication \\
\hline
\end{tabular}

* GRAIL is the Gravity Recovery and Interior Laboratory, LLR is Lunar Laser Ranging, and LOLA is the Lunar Orbiter Laser Altimeter.

Kuwabara et al., 2016; Steenstra et al., 2016; Terasaki et al., 2019; Deng et al., 2019; Knibbe et al., 2021).

Along with density, an important constraint on the composition and inner structure of the core is placed by experimental measurements of the $P$-wave velocities in liquid $\mathrm{Fe}$ alloys, which make it possible comparison with the speed of sound in the Moon's central region, according to Apollo data. The composition of the core is still unknown, and hence, several candidate elements shall be discussed (Fig. 9).

All light elements variably decrease the density of iron alloys. The situation with the speed of sound $\left(V_{P}\right)$ is more complicated. The $V_{P}$ of liquid $\mathrm{Fe}-\mathrm{Ni}, \mathrm{Fe}-\mathrm{S}$, $\mathrm{Fe}-\mathrm{C}$, and $\mathrm{Fe}-\mathrm{Si}$ were lately measured in high-pressure static experiments by ultrasonic technique at pressures below $10 \mathrm{GPa}$ and by the inelastic X-ray scattering at pressures above $10 \mathrm{GPa}$. These results show that $\mathrm{S}, \mathrm{C}$, and Ni decrease $V_{P}$ of liquid Fe at pressures below $10 \mathrm{GPa}$, whereas $\mathrm{S}$ and $\mathrm{C}$ increase $V_{P}$ of liquid $\mathrm{Fe}$ at pressures above $10 \mathrm{GPa}$ (Jing et al., 2014; Kuwabara et al., 2016; Nishida et al., 2016; Shimoyama et al., 2016; Nakajima et al., 2015). The likely explanation of this tendency is changes in the structure and electron properties of liquid $\mathrm{Fe}-\mathrm{S}$. Experimental data generally indicate that the presence of both $\mathrm{C}$ and $\mathrm{Si}$ increase $V_{P}$ of liquid $\mathrm{Fe}$, at least under pressures up to $20 \mathrm{GPa}$ (Jing et al., 2015; Terasaki et al., 2019; Knibbe et al., 2021), in contrast to the effect of S (Nishida et al., 2020).

Figure 9 shows that the values of $V_{P}$ of liquid $\mathrm{Fe}(\mathrm{Ni})-\mathrm{S}-\mathrm{C}-\mathrm{Si}$ alloys depend on the admixture element and on its concentration. The values measured at $5 \mathrm{GPa}$ vary from $V_{P} \sim 3700 \mathrm{~m} / \mathrm{s}$ for Fe-10 wt \% S (Jing et al., 2014), to $V_{P} \sim 3900-4100 \mathrm{~m} / \mathrm{s}$ for $\mathrm{Fe}-3$ to 13 wt $\%$ S (Kuskov and Belashchenko, 2016; Nishida et al., 2016, 2020; Terasaki et al., 2019), $V_{P} \sim 4200 \mathrm{~m} / \mathrm{s}$ for $\mathrm{Fe}-\mathrm{Ni}$ and $\sim 4400 \mathrm{~m} / \mathrm{s}$ for $\mathrm{Fe}$ (Kuwabara et al., 2016; Nishida et al., 2016, 2020), to $V_{P} \sim 4500 \mathrm{~m} / \mathrm{s}$ for $\mathrm{Fe}(\mathrm{Ni})-3$ to 5 wt \% C (Nakajima et al., 2015; Kuwabara et al., 2016; Zhu et al., 2021) and to $V_{P} \sim 4700 \mathrm{~m} / \mathrm{s}$ for $\mathrm{Fe}-\mathrm{Si}$ and $\mathrm{Fe}(\mathrm{Ni})-10$ to $17 \mathrm{wt} \% \mathrm{Si}$ liquid alloys (Jing et al., 2015; Terasaki et al., 2019). The presence of minor $\mathrm{C}$ concentrations in $\mathrm{Fe}-\mathrm{Si}$ alloy does not any significantly modify the aforementioned tendency, and moreover, the solubility of $\mathrm{C}$ in liquid metal decreases with increasing $\mathrm{Si}$ concentration (Knibbe et al., 2021) and, perhaps, also the Ni concentration. The solubility of S, C, and Si in liquid Fe strongly depends on the redox conditions in the interiors of the planetary body. Inasmuch as oxygen fugacity in the lunar mantle was evaluated at $\Delta \mathrm{IW} \sim-2$ (Wieczorek et al., 2006; Rai and van Westrenen 2014), the occur- 
rence of $\mathrm{Si}$ in the $\mathrm{Fe}$ core when it was formed is deemed to be less probable than in the core of Mercury, in which $f \mathrm{O}_{2}$ was estimated at 3.2 to $7.3 \log$ units below the $\mathrm{Fe}-\mathrm{FeO}$ buffer (Knibbe et al., 2021).

It is interesting to compare the seismic estimates of the speed of sound in the liquid core with ultrasonic measurements in the liquid alloys (Fig. 9). No wave velocities in the liquid core were determined in (Garcia et al., 2011). The speed of sound in the liquid outer core was assumed in (Weber et al., 2011) to be $V_{P}=$ $4100 \pm 200 \mathrm{~m} / \mathrm{s}( \pm 5 \%)$ on the basis of experimental measurements of physical properties of Fe melts. Then the speed of sound in liquid $\mathrm{Fe}-10 \% \mathrm{Ni}$ and $\mathrm{Fe}$ shall be only $5-7 \%$ higher than in the outer core (Fig. 9). The speed of sound $\left(V_{P} \sim 4500-4700 \mathrm{~m} / \mathrm{s}\right)$ for liquid $\mathrm{Fe}(\mathrm{Ni})-3$ to $5 \mathrm{wt} \% \mathrm{C}$ and $\mathrm{Fe}(\mathrm{Ni})-10$ to $17 \mathrm{wt} \% \mathrm{Si}$ is higher than $V_{P}$ for liquid $\mathrm{Fe}$ and $\mathrm{Fe}-\mathrm{Ni}$ (Kuwabara et al., 2016; Terasaki et al., 2019; Knibbe et al., 2021; Jing et al., 2015; Zhu et al., 2021).

Hence, the speed of sound in $\mathrm{Fe}-\mathrm{Ni}-\mathrm{C}$ and $\mathrm{Fe}-$ $\mathrm{Ni}-\mathrm{Si}$ melts is higher than $4500 \mathrm{~m} / \mathrm{s}$ (Fig. 9), which is $10 \%$ higher than $V_{P}$ in the outer core, according to (Weber et al., 2011). If the seismic model is accurate enough, liquid $\mathrm{Fe}(\mathrm{Ni})$ melts with an admixture of $\mathrm{C}$ (and, particularly, Si) as a light element are hardly probable and can be rejected from consideration (with a certain probability) on the basis of ultrasonic measurements in $\mathrm{Fe}(\mathrm{Ni})-\mathrm{C}$ and $\mathrm{Fe}(\mathrm{Ni})-\mathrm{Si}$ liquids and because of too oxidizing conditions during the origin of the lunar core for $\mathrm{Fe}(\mathrm{Ni})-\mathrm{Si}$.

Only the $V_{P} \sim 3900-4100 \mathrm{~m} / \mathrm{s}$ (Kuskov and Belashchenko, 2016; Nishida et al., 2016, 2020; Terasaki et al., 2019) of $\mathrm{Fe}(\mathrm{Ni})-\mathrm{S}$ liquid alloys (up to $\sim 16$ at \% $\mathrm{S} / \sim 10 \mathrm{wt} \% \mathrm{~S}$ ) fall within this range of uncertainty, which is consistent with 6-8 wt \% S in the lunar core, according to data on the distribution of siderophile elements between silicate melt and liquid metallic alloy (Rai and van Westrenen 2014; Steenstra et al., 2016). However, the speed of sound in $\mathrm{Fe}-10 \% \mathrm{Ni}$ liquids is consistent, within the errors, with the seismic estimate of the model (Weber et al., 2011).

If sulfur (with some uncertainty in its content) is the only light element in the liquid outer core, then its density and the speed of sound lie within the ranges of $6200-7000 \mathrm{~kg} / \mathrm{m}^{3}$ (Figs. 6, 8) and 3900-4100 m/s, respectively (Fig. 9). At $5 \mathrm{GPa}$, the density of solid bcc-Fe at $1811 \mathrm{~K}$ is $\rho=7620 \mathrm{~kg} / \mathrm{m}^{3}$ (Dorogokupets et al., 2014). If the solid inner core consists of bcc-Fe, fcc-Fe, and $\mathrm{Fe}(\mathrm{Ni})$ alloy or $\mathrm{Fe}(\mathrm{Ni})$ alloy with minor admixtures of light elements ( $\mathrm{S}$ or $\mathrm{C}$ ), then its density shall be $7500-7700 \mathrm{~kg} / \mathrm{m}^{3}$ (Antonangeli et al., 2015; Dorogokupets et al., 2014; Kuskov and Belashchenko, 2016), which is a little bit lower than assumed in the seismic model (Weber et al., 2011) (Fig. 8). A change in the density for $500-1000 \mathrm{~kg} / \mathrm{m}^{3}$ can be explained by the difference between the compositions of the inner and outer core, which shall likely lead to strong reflec- tions from the inner core boundary at a radius of $240 \pm$ $10 \mathrm{~km}$ in the model (Weber et al., 2011).

\section{CONCLUSIONS}

The joint inversion of directly unrelated seismic, selenophysical, and geochemical $\left(M, I / M R^{2}, T_{P}, T_{S}\right.$, $k_{2}, Q,(\mathrm{FeO})_{\text {bulk }}$, and $\left.\left(\mathrm{Al}_{2} \mathrm{O}_{3}\right)_{\text {bulk }}\right)$ parameters was carried out to simulate the chemical composition of the mantle and the inner structure of the central region of the Moon with a radius of approximately $500-550 \mathrm{~km}$. The results thus obtained make it possible to interrelate sets of geophysical, geochemical, and physicochemical parameters on a fundamental basis and to determine more reliable constraints for the inner structure of the central zone and for the chemical composition, physical properties, and size of the Moon's core.

These results show that the thickness of the partially molten layer and the radii of the outer and inner core only insignificantly depend on the composition of the bulk silicate Moon. FeO concentrations are unified for models $\mathrm{E}$ and $\mathrm{M}$ and are almost constant, 1213 wt \%, in all mantle zones. The bulk silicate Moon (its core + mantle) is enriched in $\mathrm{FeO}(12-13$ wt \%, $\mathrm{FeO} \sim 1.5 \times \mathrm{BSE})$ and depleted in $\mathrm{MgO}(\mathrm{Mg} \# 79-81)$ relative to $\mathrm{BSE}(\mathrm{FeO} \sim 8 \%$ and $\mathrm{Mg} \# 89$ ). This likely undeniable fact rules out the possibility that the Moon was formed from the material of the primitive Earth's mantle without invoking additional ad hoc hypotheses (Hosono et al., 2019) and cannot be adequately explained in either canonical or noncanonical models for the origin of the Moon within the scope of the Giant Impact hypothesis (Discussion Meeting Issue, 2014; Canup, 2014).

$\mathrm{SiO}_{2}$ concentrations vary insignificantly in all zones of the lunar mantle and are 52-53 wt \%, and the dominant mineral of the upper mantle is low-Ca orthopyroxene but not olivine. Conversely, the mantle is stratified in terms of $\mathrm{Al}_{2} \mathrm{O}_{3}$ concentration, which is higher in the lower mantle and in overlying shells. The increase in the $\mathrm{Al}$ concentration in the lower mantle results in an increase in the content of garnet relative to those of spinel and orthopyroxene.

The significant difference between $\mathrm{FeO}$ concentrations in the Earth and Moon puts forth the problem of the mechanism that could have enriched the Moon in this component. According to the canonical model (Canup, 2004), the Moon was produced by a collision between the Earth and a cosmic body referred to as Theia, whose size was about the size of Mars, with the bulk of the Moon's material borrowed from the impactor. In this situation, the isotope composition of the Moon would have reflected that of Theia. This hypothesis faces certain difficulties, which are, first of all, of geochemical nature (Galimov, 2011, 2019), because an impactor produced in its own isotope reservoir in the Solar System would have an isotope com- 
position different from that of the Earth, and hence, the composition of lunar and terrestrial samples would also have been different. However, measurements indicate that lunar and terrigenous rocks are largely isotopically similar, i.e., the isotope compositions of a number of elements (oxygen, silicon, chromium, titanium, and tungsten) in the Earth and the hypothetical planet Theia are closely similar (Armytage et al., 2012; Dauphas et al., 2014), which is in conflict with the canonical model for the origin of the Moon as a result of the giant impact. According to this hypothesis, the Moon was formed dominantly from the material of Theia. This leads to the hypothesis that the Moon consists mostly of material received from the mantle of the proto-Earth (Ringwood, 1977) or from the material of an impactor whose isotope composition was identical to that of the Earth (Dauphas et al., 2014).

At the same time, as demonstrated in this study, the enrichment of the Moon in $\mathrm{FeO}$ rules out its origin from the material of the Earth's primitive mantle, which is consistent with earlier data (Kuskov and Kronrod, 2000; Lognonné et al., 2003; Khan et al., 2007; Kronrod and Kuskov, 2011; Sakai et al., 2014; Kuskov et al., 2019a, 2019b) and, hence, implies that $12-13$ wt $\% \mathrm{FeO}$ of the lunar material was inherited mostly from the massive protoplanet Theia with a higher $\mathrm{FeO}$ concentration. This implies that both the impactor and the proto-Earth were produced of the material of a common isotope reservoir in the inner Solar System (Nielsen et al., 2021). In any event, the enrichment of the Moon in $\mathrm{FeO}$ is of fundamental importance and shall impose additional constraints, which shall be taken into considerations when cosmogenic concepts are developed for the origin of the Moon and when dynamic processes that formed the Earth-Moon system are modeled.

The transition layer surrounding the core and occurring at depths of $\sim 1200-1400 \mathrm{~km}$ has a thickness of $200-250 \mathrm{~km}$ and a density of $\geq 3400 \mathrm{~kg} / \mathrm{m}^{3}$. The latter is typical of the density of lunar black glasses with high $\mathrm{FeO}$ and $\mathrm{TiO}_{2}$ concentrations (van Kan Parker et al., 2012; Khan et al., 2014). The radius of the supposedly solid inner core $R_{i c} \sim 50-250 \mathrm{~km}$, and the most probable radius of the liquid outer core, which only insignificantly depends of the Moon's thermal state, is $300-350 \mathrm{~km}$ ( $1 \%$ of the Moon's mass), which is consistent with geophysical constraints (Weber et al., 2011; Garcia et al., 2011; Williams et al., 2014; Matsumoto et al., 2015).

Comparison of physical characteristics of the core with experimental measurements of its density indicates that the densities of liquid iron alloys with up to $\sim 10$ wt $\%$ light elements (sulfur, carbon, and/or silicon) at $5 \mathrm{GPa}$ are $6200-7000 \mathrm{~kg} / \mathrm{m}^{3}$, with these values lying within the range of the inverted values of the density of the outer core (Fig. 6) but are $20-40 \%$ higher than the density of the outer core (Fig. 8) according to seismic models (Garcia et al., 2011; Weber et al., 2011).
Another important constraint on the composition and physical properties of the Moon's core is the speed of sound. Under core pressures measured by ultrasonic techniques, these values vary from $V_{P} \sim 3900-$ $4100 \mathrm{~m} / \mathrm{s}$ for $\mathrm{Fe}(\mathrm{Ni})-\mathrm{S}$ to $V_{P} \sim 4200-4400 \mathrm{~m} / \mathrm{s}$ for $\mathrm{Fe}-\mathrm{Ni}$ and to $V_{P} \sim 4500-4700 \mathrm{~m} / \mathrm{s}$ for liquid $\mathrm{Fe}(\mathrm{Ni})-\mathrm{C}$ and $\mathrm{Fe}(\mathrm{Ni})-\mathrm{Si}$ alloys (Fig. 9). If, presumably, the seismic model (Weber et al., 2011) is reasonably accurate, and the error in $V_{P}=4100 \pm 200 \mathrm{~m} / \mathrm{s}$ is $5 \%$, then the speed of sound only in liquid $\mathrm{Fe}(\mathrm{Ni})-\mathrm{S}$ (up to $\sim 10 \mathrm{wt} \% \mathrm{~S}$ ) and, perhaps, also $\mathrm{Fe}-10 \% \mathrm{Ni}$ falls at $5 \mathrm{GPa}$ within this uncertainty range (Kuwabara et al., 2016; Kuskov and Belashchenko, 2016; Terasaki et al., 2019; Nishida et al., 2016, 2020), which is consistent with 6-8 wt \% S in the lunar core according to data on metal-silicate distribution of siderophile elements (Rai and van Westrenen, 2014; Steenstra et al., 2016). The values of $V_{P}=4000-5000 \mathrm{~m} / \mathrm{s}$ for the outer core inverted in this study fairly probably fall within the measurement space of the speed of sound in liquid $\mathrm{Fe}(\mathrm{Ni})-\mathrm{S}$ alloys.

The $V_{P}$ values of liquid $\mathrm{Fe}-\mathrm{Ni}-\mathrm{C}$ and $\mathrm{Fe}-\mathrm{N}-\mathrm{Si}$ alloys are higher than seismic estimates for the speed of sound in the liquid outer core of the Moon. Because the solubility of S, C, and $\mathrm{Si}$ in liquid Fe depends on the oxygen fugacity, which was evaluated at $\Delta \mathrm{IW} \sim-2$ for the Moon's interiors, liquid $\mathrm{Fe}(\mathrm{Ni})$ alloys with admixtures of $\mathrm{C}$ (and particularly $\mathrm{Si}$ ) as a light element can hardly occur in the Moon's outer core and can thus be rejected from the considerations by virtue of the ultrasonic measurements in $\mathrm{Fe}(\mathrm{Ni})-\mathrm{C}$ and $\mathrm{Fe}(\mathrm{Ni})-\mathrm{Si}$ liquids and because the conditions were too oxidizing for $\mathrm{Fe}(\mathrm{Ni})-\mathrm{Si}$ when the core was formed. For the same reason, $\mathrm{Fe}-\mathrm{Si}$ alloy can also be rejected as the basis for the Moon's inner core. This is consistent with the $\mathrm{Si}$ isotope signature $\left(\delta^{30} \mathrm{Si}\right)$ of the Moon (Armytage et al., 2012), which is identical to that of the Earth and makes it possible to rule out $\mathrm{Si}$ as a component of the lunar core. According to (Xia et al., 2019), isotope $\mathrm{Cu}$ concentration in BSM rules out $\mathrm{C}$ as a significant light element in the core. It is hardly probable that the Moon's core contains oxygen because the conditions were too reducing when the core was formed.

The inner Fe-Ni core (perhaps, with an insignificant $\mathrm{S}$ concentration) is thought to be solid and have a density of $7500-7700 \mathrm{~kg} / \mathrm{m}^{3}$. The difference between the density of the inner and outer core $\Delta \rho \sim 500-1000 \mathrm{~kg} / \mathrm{m}^{3}$ can be explained by the differences in their composition. Weber et al. (2011) reported the $V_{P}$ of the inner core (Fig. 9) and its $V_{S}=2300 \mathrm{~m} / \mathrm{s}$. No experimental determinations are so far available for $V_{P}$ and $V_{S}$ for $\mathrm{Fe}$ based solid alloys under $P-T$ parameters of the Moon's core. Such data have been acquired at suitable pressures, the temperatures were too low: $800-1200 \mathrm{~K}$ (Deng et al., 2019 and references therein). The authors report measured $V_{P}$ and $V_{S}$ for $\mathrm{Fe}_{5} \mathrm{Si}(9 \mathrm{wt} \% \mathrm{Si}$ ) alloy of BCC lattice at $2.6 \mathrm{GPa} / 800-1150 \mathrm{~K}$ and 3- 
$7 \mathrm{GPa} / 300 \mathrm{~K}$. It is difficult to compare these and seismic data because of the difference in the $P-T$ parameters of the experiment and Moon's core. It can just be mentioned that an inner core based on such alloy is hardly probable because of the insufficiently reducing conditions in the lunar interiors (relatively high values of $f \mathrm{O}_{2}, \Delta \mathrm{IW} \sim-2$ ) compared to the conditions in the Mercury's interiors.

In conclusion, it should be mentioned that the sizes of the Moon's core are notably dependent on the density of the $\mathrm{Fe}$ alloys (the concentration of $\mathrm{S}$ and/or other light admixtures) but merely insignificantly depend on petrological model of the mantle and the Moon's thermal regime (Kuskov et al., 2019a, 2019b; Kronrod et al., 2020). Completely crystalline core is incompatible with analysis of LLR and GRAIL data (Williams et al., 2001, 2014). The occurrence of a relatively small, dense, electrically conducting, and partly molten $\mathrm{Fe}(\mathrm{Ni})-\mathrm{S}$ core of the Moon with a radius of $300-350 \mathrm{~km}$, which satisfies the constraints placed on it by data of Lunar Prospector electromagnetic sounding (Hood et al., 1999; Shimizu et al., 2013) and geophysical constraints in (Garcia et al., 2011; Weber et al., 2011; Williams et al., 2014; Matsumoto et al., 2015), is consistent with the occurrence of a partly molten layer of high dissipation (Williams and Boggs, 2015; Weber et al., 2011; Khan et al., 2014), geochemical data on the depletion of the Moon in siderophile elements and metal/silicate distributions of $\mathrm{Ni}, \mathrm{Co}, \mathrm{W}, \mathrm{Mo}, \mathrm{P}$, and some other elements (Rai and van Westrenen, 2014; Steenstra et al., 2016), and experimental measurements of density and speed of sound for $\mathrm{Fe}(\mathrm{Ni})-\mathrm{S}$ melts (Nishida et al., 2016, 2020; Terasaki et al., 2019; Kuskov and Belashchenko, 2016) and do not contradict results on modeling the mechanism generating the lunar dynamo at $\sim 3-4$ Ga due to interaction between the solid silicate mantle and liquid core or the crystallization of the inner core (Williams et al., 2001; Breuer et al., 2015).

This paper is a memorial to Akad. Erik M. Galimov, who was the initiator of geochemical studies and evolution of the Earth-Moon system.

\section{FUNDING}

This study was carried out under government-financed research project 0137-2019-0004 for the Vernadsky Institute of Geochemistry and Analytical Chemistry, Russian Academy of Sciences.

\section{OPEN ACCESS}

This article is licensed under a Creative Commons Attribution 4.0 International License, which permits use, sharing, adaptation, distribution and reproduction in any medium or format, as long as you give appropriate credit to the original author(s) and the source, provide a link to the Creative Commons license, and indicate if changes were made. The images or other third party material in this article are included in the article's Creative Commons license, unless indicated otherwise in a credit line to the material. If material is not included in the article's Creative Commons license and your intended use is not permitted by statutory regulation or exceeds the permitted use, you will need to obtain permission directly from the copyright holder. To view a copy of this license, visit http://creativecommons.org/licenses/by/4.0/.

\section{REFERENCES}

V. N. Afanas'ev and G. V. Pechernikov, "On the probability of capture of planetesimal into protolunar swarm during formation of the Earth-Moon," Dynamic Processes in Geospheres, Proc. IDG RAN 11, 80-91 (2019).

D. Antonangeli, G. Morard, N. C. Schmerr, T. Komabayashi, M. Krisch, G. Fiquet, and Y. Fei, "Toward a mineral physics reference model for the Moon's core," PNAS 112, 3916-3919 (2015).

R. M. Armytage, G. R. B. Georg, H. M. Williams, and A. N. Halliday, "Silicon isotopes in lunar rocks: implications for the Moon's formation and the early history of the Earth," Geochim. Cosmochim. Acta 77, 504514 (2012).

P. S. Balog, R. A. Secco, D. C. Rubie, and D. J. Frost, "Equation of state of liquid $\mathrm{Fe}-10 \mathrm{wt} \% \mathrm{~S}$ : Implications for the metallic cores of planetary bodies," J. Geophys. Res. 108, (2003)

D. K. Belashchenko, "Estimation of the thermodynamic characteristics of the Earth's core using the Embedded Atom Model," Geochem. Int. 52 (6), 456-466 (2014).

D. Breuer, T. Rueckriemen, and T. Spohn "Iron snow, crystal floats, and inner-core growth: modes of core solidification and implications for dynamos in terrestrial planets and moons," Progress Earth Planet. Sci. 2 (1), 39 (2015).

R. M. Canup, "Lunar-forming impacts: processes and alternatives," Phil. Trans. R. Soc. A 372, 20130175 (2014).

J. T. Chen, Yu. S. Huang, J. Girard, and X. Liu, "Compressibility of liquid FeS measured using X-ray radiograph imaging," Phys. Earth Planet. Inter. 228, 294299 (2014).

N. Dauphas, C. Burkhardt, P. H. Warren, and T. FangZhen, "Geochemical arguments for an Earth-like Moon-forming impactor," Phil. Trans. R. Soc. A. 372, 20130244 (2014).

S. I. Demidova, M. A. Nazarov, C. A. Lorenz, G. Kurat, F. Brandstätter, and Th. Ntaflos "Chemical composition of lunar meteorites and the lunar crust," Petrology 15, 386-407 (2007).

L. Deng, Y. Kono, and G. Shen, "Sound wave velocities of $\mathrm{Fe}_{5} \mathrm{Si}$ at high-pressure and high-temperature conditions: Implications to lunar and planetary cores," Am. Mineral. 104, 291-299 (2019).

"Discussion Meeting Issue 'Origin of the Moon: challenges and prospects," organised and edited by D. J. Stevenson and A. N. Halliday," Phil. Trans. R. Soc. A. 372 (2014).

P. I. Dorogokupets, T. S. Sokolova, and K. D. Litasov, "Thermodynamic properties of bcc-Fe to melting temperature and pressure to $15 \mathrm{GPa}$," Geodynam. Tectonophys. 5, 1033-1044 (2014).

J. Gagnepain-Beyneix, P. Lognonné, H. Chenet, D. Lombardi, and T. Spohn, "A seismic model of the lunar 
mantle and constraints on temperature and mineralogy,” Phys. Earth Planet. Inter. 159, 140-166 (2006).

E. M. Galimov, "Formation of the Moon and the Earth from a common supraplanetary gas dust cloud. Lecture Presented at the XIX All-Russia Symposium on Isotope Geochemistry, November 2010," Geochem. Int. 49 (6), 537-554 (2011).

E. M. Galimov, "Geochemical features of the Moon and Earth predetermined by the mechanism of formation of the Earth-Moon System (Report at the 81st International Meteorite Conference, Moscow, July 2018)," Geochem. Int. 64 (8), 837-850 (2019).

E. M. Galimov, "Problems of the Moon origin," Main Directions in Geochemistry. On 100 ${ }^{\text {th }}$ Anniversary of Academician A.P. Vinogradov (Nauka, Moscow, 1995), pp. 8-43.

E. M. Galimov and A. M. Krivtsov, Origin of the Moon. New Concept. Geochemistry and Dynamics (De Gruyter, 2012).

R. F. Garcia, A. Khan, M. Drilleau, L. Margerin, T. Kawamura, D. Sun, M. A. Wieczorek, A. Rivoldini, C. Nunn, R. C. Weber, A. G. Marusiak, P. Lognonné, Y. Nakamura, and P. Zhu, "Lunar seismology: an update on interior structure models, Space Sci. Rev. 215 (50), (2019).

R. F. Garcia, J. Gagnepain-Beyneix, S. Chevrot, and P. Lognonné, "Very preliminary reference Moon model,” Phys. Earth Planet. Inter. 188, 96-113(2011).

Y. Harada, S. Goossens, K. Matsumoto, J. Yan, J. Ping, H. Noda, and J. Haruyama, "Strong tidal heating in an ultralow-viscosity zone at the core-mantle boundary of the Moon," Nat. Geosci. 7, 569-572 (2014).

W. K. Hartmann, "The giant impact hypothesis: past, present (and future?)," Phil. Trans. R. Soc. A. 372: 20130249 (2014).

L. L. Hood, D. L. Mitchell, R. P. Lin, M. H. Acuña, and A. B. Binder, "Initial measurements of the lunar induced magnetic dipole moment using lunar prospector magnetometer data," Geophys. Res. Lett. 26, 23272330 (1999).

N. Hosono, S. Karato, J. Makino, and T. R. Saitoh, "Terrestrial magma ocean origin of the Moon," Nature Geosci. (2019)

https://doi.org/10.1038/s41561-019-0354-2

https://doi.org/10.1038/s41586-019-1189-0

E. Jarosewich, "Chemical analyses of meteorites: a compilation of stony and iron meteorite analyses," Meteoritics 25, 323-337 (1990).

Z. Jing, Y. Wang, Y. Kono, T. Yu, T. Sakamaki, C. Park, M. L. Rivers, S. R. Sutton, and G. Shen, "Sound velocity of $\mathrm{Fe}-\mathrm{S}$ liquids at high pressure: Implications for the Moon's molten outer core," Earth Planet. Sci. Lett. 396, 78-87 (2014).

Z. Jing, J. Han, T. Yu, and Y. Wang, "Sound velocity and equation of state of iron-silicon and iron-carbon liquids under planetary core conditions," 46th Lunar Planet. Sci. Conf., LPI Contrib. No. 2921 (2015).

J. H. Jones and J. W. Delano, "A three component model for the bulk composition of the Moon," Geochim. Cosmochim. Acta. 53, 513-527 (1989).

S. Kamata, I. Matsuyama, and F. Nimmo, "Tidal resonance in icy satellites with subsurface oceans," J. Geophys. Res. Planets 120, 1528-1542 (2015).
S.-I. Karato, "Geophysical constraints on the water content of the lunar mantle its implications for the origin of the Moon," Earth Planet. Sci. Lett. 384, 144-153 (2013).

A. Khan, J. A. D. Connolly, N. Olsen, and K. Mosegaard, "Constraining the composition and thermal state of the Moon from an inversion of electromagnetic lunar dayside transfer functions," Earth Planet. Sci. Lett. 248, 579-598 (2006).

A. Khan, J. A. D. Connolly, J. Maclennan, and K. Mosegaard, "Joint inversion of seismic and gravity data for lunar composition and thermal state," Geophys. J. 168, 243-258 (2007).

A. Khan, J. A. D. Connolly, A. Pommier, and J. Noir, "Geophysical evidence for melt in the deep lunar interior and implications for lunar evolution," J. Geophys. Res. Planets 119, 2197-2221 (2014).

J. S. Knibbe, A. Rivoldini, S. M. Luginbuhl, O. Namur, B. Charlier, M. Mezouar, D. Sifre, J. Berndt, Y. Kono, D. R. Neuville, W. van Westrenen, and T. Van Hoolst, "Mercury's interior structure constrained by density and $\mathrm{P}-$ wave velocity measurements of liquid $\mathrm{Fe}-\mathrm{Si}-\mathrm{C}$ alloys," J. Geophys. Res.: Planets 126, e2020JE006651 (2021).

E. Kronrod, K. Matsumoto, O. Kuskov, V. Kronrod, R. Yamada, and S. Kamata, "Joint inversion of geophysical (seismic and selenodetic) and geochemical data for internal structure and composition of the Moon," IOP Conf. Ser.: Mater. Sci. Eng. 468012015 (2018).

E. Kronrod, K. Matsumoto, O. Kuskov, V. Kronrod, R. Yamada, and S. Kamata, "The effect of temperature distribution in the lunar mantle on joint inversion of geochemical (bulk chemical composition), seismic and selenodetic (GRAIL and LLR) data," J. Phys.: Conf. Ser. 1301012001 (2019).

E. Kronrod, O. Kuskov, K. Matsumoto, and V. Kronrod, "Estimation of the probable size of the lunar core based on geophysical and geochemical data," J. Phys.: Conf. Ser. 1705012024 (2020).

V. A. Kronrod and O. L. Kuskov, "Inversion of seismic and gravity data for the composition and core sizes of the Moon," Izv. Phys. Solid Earth 47, 711-730 (2011).

O. L. Kuskov, "Chemical composition of the Earth's core," Geokhimiya, No. 9, 1267-1292 (1981).

O. L. Kuskov and D. K. Belashchenko, "Thermodynamic properties of $\mathrm{Fe}-\mathrm{S}$ alloys from molecular dynamics modeling: Implications for the lunar fluid core," Phys. Earth Planet. Inter. 258, 43-50 (2016).

O. L. Kuskov and V. A. Kronrod, "Resemblance and difference between the constitution of the Moon and Io," Planet. Space Sci. 48, 717-726 (2000).

O. L. Kuskov and V. A. Kronrod, "Geochemical constraints on the model of the composition and thermal conditions of the Moon according to seismic data," Izv. Phys. Solid Earth 45, 753-768 (2009).

O. L. Kuskov, R. F. Galimzyanov, L. M. Truskinovsky, and V. A Pil'chenko, "Reliability of thermodynamic calculations of chemical and phase-equilibria at high-pressures and temperatures," Geokhimiya, No. 6, 849-871 (1983).

O. L. Kuskov, O. B. Fabrichnaya, R. F. Galimsyanov, and L. M. Truskinovsky, "Computer simulation of the phase diagram for the $\mathrm{MgO}-\mathrm{SiO}_{2}$ system at $\mathrm{P}-\mathrm{T}$ parameters of the mantle transition zone," Phys. Chem. Minerals 16, 442-454 (1989). 
O. L. Kuskov, V. A. Kronrod, and A. A. Prokof'ev, “Thermal structure and thickness of the lithospheric mantle underlying the Siberian Craton from the Kraton and Kimberlit superlong seismic profiles,” Izv. Phys. Solid Earth 47, 155-175 (2011). https://doi.org/10.1134/S106935131011101

O. L. Kuskov, V. A. Kronrod, and E. V. Kronrod, "Thermochemical constraints on the interior structure and composition of the lunar mantle," Phys. Earth Planet. Inter. 235, 84-95 (2014).

O. L. Kuskov, E. V. Kronrod, and V. A. Kronrod, "Thermo-chemical constraints on the lunar bulk composition and the structure of a three-layer mantle," Phys. Earth Planet. Inter. 286, 1-12 (2019a).

O. L. Kuskov, E. V. Kronrod, and V. A. Kronrod, "Effect of thermal state on the mantle composition and core sizes of the Moon," Geochem. Int. 57, 605-620 (2019b).

S. Kuwabara, H. Terasaki, K. Nishida, Y. Shimoyama, Y. Takubo, Y. Higo, Y. Shibazaki, S. Urakawa, K. Uesugi, A. Takeuchi, and T. Kondo, "Sound velocity and elastic properties of $\mathrm{Fe}-\mathrm{Ni}$ and $\mathrm{Fe}-\mathrm{Ni}-\mathrm{C}$ liquids at high pressure," Phys. Chem. Min. 43, 229-236 (2016).

E. B. Lebedev, V. V. Averin, O. A. Lukanin, I. A. Roshchina, N. N. Kononkova, and E. A. Zevakin, "Effect of redox conditions on iron metal phase segregation during experimental high-temperature centrifuge modeling of the origin of the Moon's core," Geochem. Int. 54, 609-617 (2016).

M. Lemelin, P. G. Lucey, K. Miljkovic, L. R. Gaddis, T. Hare, and M. Ohtake, "The compositions of the lunar crust and upper mantle: Spectral analysis of the inner rings of lunar impact basins," Planet. Space Sci. 165, 230-243 (2019).

B. Yu. Levin and S. V. Maeva, Puzzle of the Origin and Thermal History of the Moon. Cosmochemistry of the Moon and Planets, Ed. by A. P. Vinogradov (Nauka, Moscow, 1975), pp. 283-298 [in Russian].

C. Li, D. Liu, B. Liu, X. Ren, J. Liu, Z. He, W. Zuo, X. Zeng, R. Xu, X. Tan, X. Zhang, W. Chen, R. Shu, W. Wen, Y. Su, H. Zhang, and Z. Ouyang, "Chang'E-4 initial spectroscopic identification of lunar far-side mantlederived materials," Nature 569, 378-382 (2019).

K. D. Litasov and A. F. Shatsky, Composition and Structure of the Earth's Core (SO RAN, Novosibirsk, 2016) [in Russian].

S. J. Lock, S. T. Stewart, M. I. Petaev, and S. B. Jacobsen, "A terrestrial synestia: a new environment for formation of the Moon," 50th Lunar Planet. Sci. Conf., LPI Contrib., No. 2132, (2019).

P. Lognonné, "Planetary seismology," Annu. Rev. Earth Planet. 33, 571-604 (2005).

P. Lognonné, J. Gagnepain-Beyneix, and H. Chenet, "A new seismic model of the Moon: implications for structure, thermal evolution and formation of the Moon,” Earth Planet. Sci. Lett. 211, 27-44 (2003).

J. Longhi, "Petrogenesis of picritic mare magmas: Constraints on the extent of early lunar differentiation," Geochim. Cosmochim. Acta 70, 5919-5934 (2006).

K. Matsumoto, R. Yamada, F. Kikuchi, S. Kamata, Y. Ishihara, T. Iwata, H. Hanada, and S. Sasaki, "Internal structure of the Moon inferred from Apollo seismic data and selenodetic data from GRAIL and LLR," Geophys. Res. Lett. 42 (2015).

https://doi.org/10.1002/2015GL065335
I. Matsuyama, F. Nimmo, J. T. Keane, N. H. Chan, G. J. Taylor, M. A. Wieczorek, W. S. Kiefer, and J. G. Williams, "GRAIL, LLR, and LOLA constraints on the interior structure of the Moon," Geophys. Res. Lett. 43, 8365-8375 (2016).

https://doi.org/10.1002/2016GL069952

G. Morard, J. Bouchet, A. Rivoldini, D. Antonangeli, M. Roberge, E. Boulard, A. Denoeud, and M. Mezouar, "Liquid properties in the Fe-FeS system under moderate pressure: Tool box to model small planetary cores," Am. Mineral. 103, 1770-1779 (2018).

J. W. Morgan, J. Hertogen, and E. Anders, "The Moon: composition determined by nebula processes," Moon and Planets 18, 465-478 (1978).

D. P. Moriarty, R. N. Watkins, S. N. Valencia, J. D. Kendall, A. J. Evans, N. Dygert, and N. E. Petro, "Evidence for a stratified upper mantle preserved within the south pole-Aitken Basin," J. Geophys. Res.: Planets 121, (2021), e2020JE006589.

Y. Nakajima, S. Imada, K. Hirose, T. Komabayashi, H. Ozawa, S. Tateno, S. Tsutsui, Y. Kuwayama, and A. Q. R. Baron, "Carbon-depleted outer core revealed by sound velocity measurements of liquid iron-carbon alloy," Nature Comm. 6, 8942 (2015).

Y. Nakamura, "Farside deep moonquakes and deep interior of the Moon," J. Geophys. Res. 110, (2005). https://doi.org/10.1029/2004JE002332

S. G. Nielsen, D. V. Bekaert, and M. Auro, "Isotopic evidence for the formation of the Moon in a canonical giant impact," Nat. Comm. 12, 1817 (2021). https://doi.org/10.1038/s41467-021-22155-7

F. Nimmo, U. H. Faul, and E. J. Garnero, "Dissipation at tidal and seismic frequencies in a melt-free Moon," J. Geophys. Res. 117, (2012). E09005.

K. Nishida, A. Suzuki, H. Terasaki, Y. Shibazaki, Y. Higo, S. Kuwabara, Y. Shimoyama, M. Sakurai, M. Ushioda, E. Takahashi, T. Kikegawa, D. Wakabayashi, and N. Funamori, "Towards a consensus on the pressure and composition dependence of sound velocity in the liquid Fe-S system," Phys. Earth Planet. Inter. 257, 230-239 (2016).

K. Nishida, Y. Shibazaki, H. Terasaki, Y. Higo, A. Suzuki, N. Funamori, and K. Hirose, "Effect of sulfur on sound velocity of liquid iron under Martian core conditions," Nat. Comm. 11, 1954 (2020). https://doi.org/10.1038/s41467-020-15755-2

A. Pommier, "Influence of sulfur on the electrical resistivity of a crystallizing core in small terrestrial bodies," Earth Planet. Sci. Lett. 496, 37-46 (2018).

S. N. Raevskiy, T. V. Gudkova, O. L. Kuskov, and V. A. Kronrod, "On reconciling the models of the interior structure of the Moon with gravity data," Izv., Phys. Solid Earth 51 (1), 134-142 (2015).

N. Rai and W. van Westrenen, "Lunar core formation: New constraints from metal-silicate partitioning of siderophile elements," Earth Planet. Sci. Lett. 388, 343-352 (2014).

K. Righter, B. M. Go, K. A. Pando, L. Danielson, D. K. Ross, Z. Rahman, and L. P. Keller, "Phase equilibria of a low $\mathrm{S}$ and $\mathrm{C}$ lunar core: Implications for an early lunar dynamo and physical state of the current core,” Earth Planet. Sci. Lett. 463, 323-332 (2017).

A. E. Ringwood, "Basaltic magmatism and the bulk composition of the Moon. I. Major and heat-producing elements," The Moon 16, 389-423 (1977). 
A. E. Ringwood and E. Essene, "Petrogenesis of Apollo 11 basalts, internal constitution and origin of the Moon," Proc. Apollo 11 Lunar Sci. Conf. 1, 769-799 (1970).

E. L. Ruskol, Origin of the Earth-Moon System (OIFZ RAN, Moscow, 1997) [in Russian].

R. Sakai, H. Nagahara, K. Ozawa, and S. Tachibana, "Composition of the lunar magma ocean constrained by the conditions for the crust formation," Icarus $\mathbf{2 2 9}$, 45-56 (2014).

C. K. Shearer, P. C. Hess, M. A. Wieczorek, M. E. Pritchard, E. M. Parmentier, L. E. Borg, J. Longhi, L. T. Elkins-Tanton, C. R. Neal, I. Antonenko, R. M. Canup, A. N. Halliday, T. L. Grove, B. H. Hager, D. C. Lee, and U. Wiechert, "Thermal and magmatic evolution of the Moon // New views of the Moon," Rev. Mineral. Geochem. 60 (1), 365-518 (2006).

H. Shimizu, M. Matsushima, F. Takahashi, H. Shibuya, and H. Tsunakawa, "Constraint on the lunar core size from electromagnetic sounding based on magnetic field observations by an orbiting satellite," Icarus 222, 32-43 (2013).

Y. Shimoyama, H. Terasaki, E. Ohtani, S. Urakawa, Y. Takubo, K. Nishida, A. Suzuki, and Y. Katayama, "Density of $\mathrm{Fe}-3.5 \mathrm{wt} \% \mathrm{C}$ liquid at high pressure and temperature and the effect of carbon on the density of the molten iron," Phys. Earth Planet. Inter. 224, 77-82 (2013).

G. A. Snyder, L. A. Taylor, and C. R. Neal, "A chemical model for generating the source of mare basalts: Combined equillibrium and fractional crystallization of the lunar magmasphere," Geochim. Cosmochim. Acta 56, 3809-3823 (1992).

P. A. Sossi and F. Moynier, "Chemical and isotopic kinship of iron in the Earth and Moon deduced from the lunar Mg-suite," Earth Planet. Sci. Lett. 471, 125-135 (2017).

E. S. Steenstra, N. Rai, J. S. Knibbe, Y. H. Lin, and W. van Westrenen, "New geochemical models of core formation in the Moon from metal-silicate partitioning of 15 siderophile elements," Earth Planet. Sci. Lett. 441, 1-9 (2016).

S. R. Taylor, G. J. Taylor, and L. A. Taylor, "The Moon: A Taylor perspective," Geochim. Cosmochim. Acta 70, 594-598 (2006).

S. R. Taylor, Planetary Science: A Lunar Perspective (Lunar Planet. Inst., Houston, 1982).

H. Terasaki, A. Rivoldini, Y. Shimoyama, K. Nishida, S. Urakawa, M. Maki, F. Kurokawa, Y. Takubo, Y. Shibazaki, T. Sakamaki, A. Machida, Y. Higo, K. Uesugi, A. Takeuchi, T. Watanuki, and T. Kondo, "Pressure and composition effects on sound velocity and density of core-forming liquids: Implication to core compositions of terrestrial planets," J. Geophys. Res.: Planets, 124 (8), 2272-2293 (2019).

N. Tsujino, Y. Nishihara, Y. Nakajima, E. Takahashi, K. Funakoshi, and Y. Higo, "Equation of state of $\gamma-F e$ : Reference density for planetary cores," Earth Planet. Sci. Lett. 375, 244-253 (2013).

H. C. Urey, "The origin and development of the earth and other terrestrial planets," Geochim. Cosmochim. Acta 1 (4-6), 209-277 (1951).
M. van Kan Parker, C. Sanloup, N. Sator, B. Guillot, E. J. Tronche, J.-P. Perrillat, M. Mezouar, N. Rai, and W. van Westrenen, "Neutral buoyancy of titaniumrich melts in the deep lunar interior," Nat. Geosci. 5, 186-189 (2012).

R. C. Weber, P. Lin, E. J. Garnero, Q. Williams, and P. Lognonné, "Seismic detection of the lunar core," Science 331, 309-312 (2011).

M. A. Wieczorek, B. J. Jolliff, A. Khan, M. E. Pritchard, B. J. Weiss, J. G. Williams, L. L. Hood, K. Righter, C. R. Neal, C. K. Shearer, I. S. McCallum, S. Tompkins, B. R. Hawke, C. Peterson, J. J. Gillis, and B. Bussey, "The constitution and structure of the lunar interior," Rev. Mineral. Geochem. 60, 221-364 (2006).

M. A. Wieczorek, G. A. Neumann, F. Nimmo, W. S. Kiefer, G. J. Taylor, H. J. Melosh, R. J. Phillips, S. C. Solomon, J. C. Andrews-Hanna, S. W. Asmar, A. S. Konopliv, F. G. Lemoine, D. E. Smith, M. M. Watkins, J. G. Williams, and M. T. Zuber, "The crust of the Moon as seen by GRAIL,” Science 339, 671-675 (2013).

J. G. Williams, and D. H. Boggs, "Tides on the Moon: theory and determination of dissipation," J. Geophys. Res.: Planets 120, 689-724 (2015).

J. G. Williams, D. H. Boggs, C. F. Yoder, J. T. Ratcliff, and J. O. Dickey, "Lunar rotational dissipation in solid body and molten core,” J. Geophys. Res. 106, 2793327968 (2001).

J. G. Williams, A. S. Konopliv, D. H. Boggs, R. S. Park, D.-N. Yuan, F. G. Lemoine, S. Goossens, E. Mazarico, F. Nimmo, R. C. Weber, S. W. Asmar, H. J. Melosh, G. A. Neumann, R. J. Phillips, D. E. Smith, S. C. Solomon, M. M. Watkins, M. A. Wieczorek, J. C. Andrews-Hanna, J. W. Head, W. S. Kiefer, I. Matsuyama, P. J. McGovern, G. J. Taylor, and M. T. Zuber, "Lunar interior properties from the GRAIL mission,” J. Geophys. Res.: Planets 119 (7), 1546-1578 (2014).

Y. Xia, E. S. Kiseeva, J. Wade, and F. Huang, "The effect of core segregation on the $\mathrm{Cu}$ and $\mathrm{Zn}$ isotope composition of the silicate Moon," Geochem. Persp. Lett. 12, 12-17 (2019).

L. Xiao and J. W. Head, Geological Characteristics of the Moon. Oxford Research Encyclopedias, (Planetary Science, 2020).

https://doi.org/10.1093/acrefore/9780190647926.013.90

S. Yu, N. Tosi, S. Schwinger, M. Maurice, D. Breuer, and L. Xiao, "Overturn of ilmenite-bearing cumulates in a rheologically weak lunar mantle,” J. Geophys. Res.: Planets 124, 418-436 (2019).

F. Zhu, X. Lai, J. Wang, G. Amulele, Y. Kono, G. Shen, Z. Jing, M. H. Manghnani, Q. Williams, and B. Chen, "Density of $\mathrm{Fe}-\mathrm{Ni}-\mathrm{C}$ liquids at high pressures and implications for liquid cores of Earth and the Moon," J. Geophys. Res.: Solid Earth 126, e2020JB021089 (2021).

https://doi.org/10.1029/2020JB021089

Translated by E. Kurdyukov 